University of Zurich

Department of Economics

Working Paper Series

ISSN 1664-7041 (print)

ISSN 1664-705X (online)

Working Paper No. 301

\title{
Womb at Work: \\ The Missing Impact of Maternal Employment on Newborn Health
}

Caroline Chuard

October 2018 


\title{
WOMB AT WORK: THE MISSING IMPACT OF MATERNAL EMPLOYMENT ON NEWBORN HEALTH
}

\author{
Caroline ChuarD* \\ University of Zurich
}

\section{This Version: October 2018}

\begin{abstract}
Parental leave policies across the globe have become much more generous than they used to be. This is also true for prenatal maternal leave. While this may be costly in the short run, little is known about the effect of maternal employment during pregnancy on newborn health. In this paper, I exploit three sharp policy changes on the duration of paid parental leave in Austria that strongly affected the share of mothers who work up to the 32 nd week of pregnancy. I use administrative data from Austria on the working history of women linked to the full Austrian birth register and coupled with a regression discontinuity framework to identify the effect of prenatal employment on their offspring. Maternal employment during pregnancy with the second child reacts strongly to these policy changes. The share of employed mothers sharply declined in 1990 by 19.1 percentage points, increased in 1996 by 7.2 percentage points and declined again by 6.4 percentage points in 2000. None of these changes in prenatal employment translated into effects on newborn health measured via birth weight, gestational length, and Apgar scores. This result holds true for mothers of different socioeconomic backgrounds and across industries. The effect is precisely estimated, which suggests that prenatal employment prior to the 32nd week of pregnancy does not causally affect the fetus for measures visible at birth.
\end{abstract}

Keywords: newborn health, maternal employment, pregnancy conditions, maternal leave; JEL classification: I10; J13; J16.

${ }^{*}$ First Version: October, 2017. University of Zurich, Department of Economics, Schönberggasse 1, 8001 Zurich, Switzerland. Email: caroline.chuard@econ.uzh.ch. Phone: +41 4463461 12. The author would like to thank the UBS International Center of Economics in Society at the University of Zurich and the Jacobs Center for Productive Youth Development for financial support.

I am grateful to Francesca Cornaglia, Patrick Keller, Johannes Kunz, Hannes Schwandt, Giuseppe Sorrenti, Josef Zweimüller, and seminar participants at the University of Zurich, the Austrian Health Economics Association Conference (ATHEA) 2017, the Young Swiss Economist Meeting (YSEM) 2018, the 1st QMUL Economics and Finance Workshop for PhD and Postdoctoral students, the IZA World Labor Conference 2018, and the 2018 HCEO Summer School on Socioeconomic Inequality Bonn. 


\section{Introduction}

Most high-income countries have seen a significant and steady increase in female labor force participation over the last few decades. Therefore, women today are much more likely to work while pregnant. At the same time, family policies have become much more generous since the turn of the century with multifold goals such as gender equity, higher fertility, and better child development (Olivetti and Petrongolo, 2017). One family policy instrument is prenatal maternity leave intended to protect both the health of the mother and the newborn. The duration of prenatal leave varies substantially - from 0 to 11 weeks - in European countries (Jurviste et al., 2016). This variation across countries mirrors the uncertainty among policy makers on how to optimally design such programs and concerning the role of maternal leave. In the fetal origins hypothesis literature, several pregnancy conditions have already been identified as key influencing factors on a variety of long-term outcomes of children. If prenatal maternal employment is among them, long-term benefits for the children may offset the costs of prenatal maternity leave. Therefore, understanding the effects of maternal employment during pregnancy on newborn health is key for policy makers who design policies concerning prenatal maternity leave.

There is a large body of literature estimating the effects of pregnancy conditions on newborn health and long-term outcomes of children as summarized by Almond and Currie (2011) and Almond et al. (2017). However, there is little evidence on the effect of prenatal employment on newborn health. This is critical because the prenatal maternal employment status combines several major aspects of pregnancy conditions such as stress, physical activity, disease environment, income, and others. In theory, the impact of prenatal employment is ambiguous. On the one hand, maternal employment during pregnancy may be stressful for the mother or may correlate with exposure to pollutants and diseases. These influences have been shown to be detrimental to the unborn baby (Aizer et al., 2015; Currie and Schwandt, 2013, 2016; Schwandt, 2017). On the other hand, employment may also increase a mother's income or may be a joyful activity itself, which therefore could improve newborn health (Almond et al., 2011; Hoynes et al., 2015).

This paper provides evidence on the effect of maternal employment during pregnancy on 
newborn health by exploiting three reforms in Austria that affected mothers' likelihood of working during pregnancy with their second child. These three reforms on the duration of parental leave allow me to employ a regression discontinuity setting. In order to empirically analyze the impact of prenatal maternal employment, I use administrative data from the Austrian Social Security Database (ASSD), which contains the full work history for privatesector employees. This data set can be linked to the Austrian Birth Register (ABR), which covers all births with several indicators on newborn health and characteristics about mothers.

Parental leave policies in Austria consist of both a flat benefit and job protection. Beginning in 1990, there have been several reforms affecting the duration of parental leave. In 1990, parental leave was extended by one year, from 12 to 24 months. In 1996, this was partially reversed to 18 months, but increased to 30 months in 2000. These changes led to an easier automatic extension for another parental leave period upon the birth of an additional child - the so called grace period rule. This rule exempts mothers from working and therefore reduces a mother's probability of working during pregnancy with the second child.

I find no evidence of prenatal employment effects on newborn health. This holds true for a variety of outcomes measured via birth weight, gestational age, and Apgar scores. Thus, I cannot reject that there are no effects of maternal employment during pregnancy on newborn health, despite a very strong first stage. Across all policy reforms, the duration of parental leave significantly affects the mother's employment status during pregnancy with her second child. The effect of the July 1990 reform, which increased parental leave by 12 months to 24 months, corresponds to a 19.1 percentage point decline in the share of mothers' working during pregnancy. This effect is homogeneous over the entire first seven months of a pregnancy. A heterogeneity analysis reveals marginally different, but always significant, effects for a large set of subsamples stratified by a mother's marital status, occupational collar, and industry. However, I detected no significant effects on newborn health for any of these subsamples.

Significantly, the study is based on a large administrative sample that allows me to precisely estimate the effects and to rule out sizeable newborn health effect-patterns. Furthermore, all covariates vary smoothly around the cutoffs of the policy reform, which supports the interpretation of the regression discontinuity; the results are robust to a variety of different 
specifications. For example, I test for different birth weight and gestational age thresholds, apply a Donut estimation to deal with delayed Caesarean sections, and implement a bounds estimator to control for selection.

This paper makes several contributions to the literature on pregnancy conditions on infant health and specifically, on prenatal maternal employment on infant health. ${ }^{1}$ Wüst (2015) employs Danish survey data in a regression analysis and finds positive effects for working mothers with closely spaced consecutive births or those who change their employment status due to educational reasons. Rossin (2011) analyzes the impact of unpaid maternity leave provisions in the United States and documents small increases in birth weight and a reduction in premature birth and infant mortality. Stearns (2015) studies time off from work during late pregnancy under a temporary disability insurance program. She finds beneficial effects for newborns of unmarried and black mothers. Ahammer et al. (2018) analyze a 1975 reform in Austria that extended prenatal maternity leave from six to eight weeks. They find no evidence for significant effects on newborn health. ${ }^{2}$

My paper adds to this literature in the following ways. It is the first to provide clear evidence of the effect of maternal employment up to and including the seventh month of a pregnancy on the health of the newborn. This setting, when combined with previous literature that focused almost exclusively on the very end of a pregnancy, helps in understanding when in pregnancy time off might be most beneficial. Using the described reforms for exogenous variation in prenatal maternal employment up to the 32 nd pregnancy week

\footnotetext{
${ }^{1}$ This study also relates to the literature studying the effects of parental leave on other types of outcomes such as maternal labor market outcomes, fertility, child and maternal health, and cognitive development of children. In the Austrian context, Lalive and Zweimüller (2009) and Lalive et al. (2013), for example, study the effect of the same reforms on maternal labor market outcomes and fertility, while Danzer and Lavy (2018) and Danzer et al. (2017) focus on cognitive outcomes of the affected children. More broadly, there is a large body of literature that studies the effect of post birth parental leave reforms on child development (Baker and Milligan, 2008; Beuchert et al., 2016; Carneiro et al., 2015; Dahl et al., 2016; Danzer and Lavy, 2018; Dustmann and Schönberg, 2012; Ruhm, 2000; Tanaka, 2005; Rasmussen, 2010). Generally, the literature concludes that introducing parental leave significantly improves child development in both the short and long run while extensions in the duration of parental leave often do not lead to significant changes in child development.

${ }^{2}$ A related study by Ginja et al. (2017) analyzes the effect of a speed premium in Sweden, analogous to the grace period in Austria. In their study, the effect of maternal employment on newborn health is not directly addressed. However, they document a slight decline in maternal employment during pregnancy with the second child and no effects on outcomes measured at birth as a result of the speed premium. The effect size of the analyzed policy reform on maternal employment is -0.013 , substantially smaller than the $0.191 \mathrm{I}$ find.
} 
generates a large and representative sample of compliers. This complements the existing literature on maternal employment during pregnancy on newborn health as I do not have to rely on differential take-up of welfare programs by rich and white mothers (as in the context of unpaid leave) or unmarried and black mothers (in the case of disability insurance). Furthermore, I am able to use a large administrative data set on an individual basis that allows me to exactly identify the exposed mothers and their offspring. Based on this data set, I can calculate the exact number of days a mother is working during pregnancy. Significantly, this allows me to analyze the impact of prenatal employment on two margins - the extensive margin of mothers who choose to work or not during pregnancy and the intensive margin of working mothers - as I can factor in unusually detailed information on maternal employment histories. The richness of the data also makes it possible to analyze heterogeneous effects across mothers and by work environment. Finally, in the Austrian context, the rich data can be combined with a diverse policy setting. I explore the impact of prenatal employment in three different points in time that allow me to both assess the effects of increases as well as decreases in employment during pregnancy. Variation in both directions allows for study of asymmetries in an already generous leave setting with strong changes in parental leave duration across the studied time period.

Overall, my results show that large changes in prenatal employment do not imply significant changes of newborn health. This suggests that parental leave policies should focus on parental leave after the birth, given that time spent with parents especially in very early childhood has been shown to be beneficial in a number of outcomes (Carneiro et al., 2015; Rossin-Slater, 2017; Heckman, 2007).

The paper is organized as follows: Section 2 describes the Austrian parental leave system and the reforms used for this study. Section 3 develops a conceptual framework on how prenatal maternal employment can affect newborn health. Section 4 discusses the data and Section 5 presents the empirical strategy. Section 6 provides an overall assessment of the results and sensitivity analyses, which will be discussed in Section 7. The paper concludes in Section 8. 


\section{The institutional setting}

The Austrian family policy rules consist of two types of policies that cover the period around birth. The first policy, mandatory maternity leave (ML), prohibits work 8 weeks pre- and post-birth and pays the average wage a mother earned during the last quarter prior to giving birth. As such, ML promises a generous environment in order to protect both the mother's and the baby's health. After mandatory maternity leave expires, eligible mothers can choose to take parental leave (PL). This second policy consists of two pillars: a flat benefit and job protection. The policy changes that I will assess in this paper affect parental leave, which will be explained in more detail below.

First-time mothers over the age of 25 are eligible for parental leave if they have worked for at least 52 weeks within the 2 years prior to giving birth. ${ }^{3}$ The work requirement is reduced to 20 weeks within the year prior to giving birth for higher-order births. ${ }^{4}$ Furthermore, there is a grace period rule that allows mothers with relatively short birth spacing an automatic extension for the next birth. More specifically, the grace period exempts mothers from the work requirement if they give birth to an additional child no later than 3.5 months after the expiration of the parental leave of the previous child.

Since 1990, there have been several reforms to the parental leave system; they are illustrated in Figure (1). Political debate about the introduction of paternal leave at the costs of maternal leave led to the compromise of extending the duration of parental leave. Furthermore, in the early 1990s, formal child care institutions were scarce in Austria. This made maternal employment during the child's early years difficult and could possibly even deter mothers from the labor market in the long run. Extending parental leave was expected to improve this situation for mothers.

The reforms were structured as follows. While parental leave lasted up to the first birthday of the child until June 1990, this was extended to 24 months after birth in July 1990. The July 1996 reform, which targeted the cash benefits but left job protection unchanged, reserved 6 of these added months for fathers. This effectively reduced the duration of parental leave to 18 months after birth because almost no fathers were taking advantage of the leave.

\footnotetext{
${ }^{3}$ Work requirements are shorter for younger mothers.

${ }^{4}$ This is changed to 26 weeks after July 1996.
} 
The July 2000 reform, which again only targeted cash transfers, increased parental leave to 36 months after birth, reserving 6 months for fathers. Therefore, it essentially increased parental leave from 18 to 30 months after birth. ${ }^{5}$

The changes in parental leave duration had strong implications for the likelihood that mothers would give birth to another child within the grace period. Prior to June 1990, a mother had to conceive the next child no later than 5.5 months after giving birth to her first child in order to meet the requirements for automatic extension, which is biologically difficult. ${ }^{6}$ The 1990 reform extended the window to conceive to 17.5 months; the July 1996 reform partially reversed it to 11.5 months, while the July 2000 reform extended it again to 23.5 months. All of these time windows are biologically feasible and desirable. ${ }^{7}$

Figure (A1) shows how the percentage of children born within parental leave and the grace period has evolved over time. By construction, longer parental leave will lead to higher fractions of second children born within this time period. Although prior to July 1990, only 10 percent of all second born were born within the period of parental leave extended by the grace period, that number increased to around 40 percent for the period from July 1990 to June 1996. In July 1996, there was a drop to 20 percent given the shorter parental leave for these cohorts. The number increased again with the very generous parental leave system established in July 2000.

Figure (2) exploits the discontinuities induced by the reforms and looks at pregnancies with second children for mothers that gave birth to their first child each of the 2 years preand post-policy reform. It shows that this simplification in meeting the requirements for the grace period in July 1990 went hand in hand with fewer women working during pregnancy with their second child. These effects are equally spread over the entire first 32 weeks of pregnancy. Thereafter, mothers go on mandatory maternity leave and do not have to work under either scheme. The decline in duration in July 1996 led to more women working during

\footnotetext{
${ }^{5}$ For further and more detailed information on the amount of cash benefits, eligibility criteria, announcement of the policy reforms, and the reforms tehmselves, see Lalive and Zweimüller (2009) and Lalive et al. (2013).

${ }^{6}$ Mothers who exclusively breastfeed have 98 percent protection from pregnancy in the first six months (Kennedy et al., 1989).

${ }^{7}$ Short (often defined as less than 18 months) and very long (more than 59 months) interpregnancy intervals are associated with adverse perinatal outcomes (see Conde-Agudelo et al. (2006) for a meta-analysis on birth spacing).
} 
the entire pregnancy, while the increase in duration in July 2000 again translated into fewer women working during pregnancy with their second child.

\section{Conceptual framework}

Prenatal maternal employment may affect newborn health through various channels. While several of these channels have each been analyzed individually in the previous literature, the combined effect of prenatal employment on newborn health is not clear a priori. I next describe each of these possible channels in more detail.

First, working itself could be stressful for the mother. Existing empirical literature on the effects of maternal stress on infant health is generally limited to studying the effects of very severe but often unique stress factors such as domestic violence (Aizer, 2011), hurricanes (Currie and Rossin-Slater, 2013), political uprising (Lee, 2014), death of a relative (Black et al., 2016; Persson and Rossin-Slater, 2018), and terrorism (Quintana-Domeque and Ródenas-Serrano, 2017; Camacho, 2008). Although all these studies show a negative impact of these events on newborn health, the effects of milder stress, for example, stress induced by work, are less clear. As recently summarized by Almond et al. (2017), relatively mild shocks in early or prenatal life can, however, have substantial negative impact on child development. Additionally, it is unclear whether mental and physical stress affect the fetus similarly and whether these stresses might cause different effects when they are experienced early or late in pregnancy.

Second, being on PL and therefore not working during pregnancy is also related to changes in income. The intensity of this effect depends on a mother's income. In fact, PL benefits are flat over the entire PL and amount to roughly $€ 340$ per month. ${ }^{8}$ This translates into income increase for low-income mothers and an income reduction for high-income mothers. However, in the literature, the income effect on newborn health is almost exclusively identified for lowincome mothers. Hoynes et al. (2015), for example, show that the Earned Income Tax Credit (EITC) in the United States reduces the incidence of low birth weight and increases mean

\footnotetext{
${ }^{8}$ According to Lalive and Zweimüller (2009) this corresponds to a median net income replacement ratio of more than 40 percent.
} 
birth weight. Almond et al. (2011) exploit monthly variation in the introduction of the Food Stamp Program (FSP) in the United States and find positive effects for birth outcomes especially at the lower tail of the birth weight distribution. Both papers focus on programs designed for low-income people. Furthermore, evidence from conditional cash transfers in developing countries also show a positive impact on several birth outcomes (Barber and Gertler, 2008; Amarante et al., 2016). However, as PL benefits are flat and therefore only negatively impact high-wage mothers, the effect of income in this setup is less clear. I will investigate this issue in a heterogeneity analysis.

Third, working during pregnancy might expose the mother to pollutants and diseases at work or while commuting. These influences have been shown to be negative for the fetus (Almond, 2006; Schwandt, 2017; Currie et al., 2009; Currie and Schwandt, 2013, 2016). Both Almond (2006) and Schwandt (2017) even show that flu exposure during pregnancy has long-term effects on children's educational attainment and wages.

Fourth, a side effect of the extension of the grace period could also be shorter birth spacing between siblings. The medical literature argues that short spacing (most often defined as less than 18 months in age difference) leads to adverse infant health outcomes (see Conde-Agudelo et al. (2006) for a meta-analysis).

\section{Data}

This project is based on two administrative data sets. The primary source of data for the determination of a mother's work status during pregnancy is the Austrian Social Security Database (ASSD). For the analysis of newborn health outcomes, I link the ASSD to the Austrian Birth Register (ABR).

The Austrian Social Security Database. The ASSD stores the full work history of privatesector employees and is used to verify pension claims. The ASSD also records the date of all live births after entering the labor market and maternity and parental leave periods if taken. As a result, I observe detailed information on a daily basis for each woman after her first entry into the labor market. Detailed labor market information consists of the employer, 
along with information on occupation, experience, and tenure. Information on earnings is provided per year and per employer.

The Austrian Birth Register. Information about newborn health measures is based on the ABR, which includes all live births in Austria. Each birth entry consists of individual-level information on birth characteristics such as date, place, gender, multiple births, gestational length, birth weight, length, and Apgar scores. Furthermore, for every birth, maternal socioeconomic characteristics such as age, educational attainment, marital status, and country of origin complement the individual-level information.

I match the two sources of data based on characteristics I observe in both data sets, such as the date of birth, the date of preceding birth for higher-order births, location of birth, and age of the mother. ${ }^{9}$ For my main analysis, I restrict my sample to private sector dependent employees who are PL eligible, aged 15-45, and who are giving birth to a singleton. ${ }^{10}$ Furthermore, I restrict my main sample to the period of 1984 to 2007, as gestational length, one of my key variables, is only recorded after 1984. Altogether, this results in approximately 60,000 observed births per year out of a total of around 85,000 births in Austria.

Finally, I construct several variables that are key for my analysis. From all birth entries per mother, I calculate the parity for every birth. Furthermore, I calculate the days a mother has been working during pregnancy and based on this, I create a dummy for the work status, defined as 1 if she worked a positive number of days during pregnancy. ${ }^{11}$

\footnotetext{
${ }^{9}$ This results in 61 percent of matches of all births in the birth register, corresponding to roughly 80 percent of all births observed in the ASSD. Once a mother leaves the labor market and gives birth to additional children, these birth dates will not be recorded in the ASSD any longer. However, based on information about the characteristics of the mother herself and the date of birth of the preceding child, I am able to recover some births that are only observed in the Austrian Birth Register. The mother's unique social security number can be added to these recovered births. This method allows me to add 87,362 births to the combined data set.

${ }^{10}$ For PL eligibility I follow the definition of Lalive and Zweimüller (2009). In order to construct the eligible sample, I consider the work history 2 years prior to giving birth to the first child. Women who show any form of employment or were eligible to collect unemployment benefits are considered eligible. This very generous form of eligibility results in 95 percent of women being eligible for PL.

${ }^{11}$ I count both normal as well as marginal employment as working days and use the terms worked and employed interchangeably. For the construction of the number of days a mother worked, gestational length in weeks (multiplied by 7 days a week) is subtracted from the exact date of birth. Working days (MO-FR) are being calculated from the day of conception to the last day of pregnancy.
} 
In addition to days worked, days sick during pregnancy can be calculated in the same manner. From this, I create a sickness dummy equaling 1 if a positive number of days sick are reported. This sickness dummy will be used as an additional explanatory variable in the OLS regression and allows me to compare my results to Wüst (2015).

For the analysis of the impact on newborn health, I use several measures of birth outcomes because these have already been shown to be linked to later-life outcomes (Almond and Currie, 2011). First, I include a dummy for low birth weight (below 2,500 grams) as a general measure. Second, I construct a dummy for prematurity equaling 1 if gestational length is less than 37 weeks. ${ }^{12}$ Additionally, I will show results for birth weight, gestational length, 1 minute Apgar score, and a dummy for a healthy Apgar score (1[Apgar $>=7])$. The Apgar score is a method of giving a quick summary of the newborn's physical health. It individually measures per category, on a scale from 0 to 2 , the newborn's skin color, heart rate, reflexes, muscle tone, and respiratory effort. A total Apgar score of 10 indicates perfect health, and an Apgar score below 7 is defined as low.

Finally, I control for the following maternal characteristics: a dummy for marital status, an indicator of foreign origin, 5-year age brackets, and an indicator combining wage and educational data. ${ }^{13}$ For the heterogeneity analysis, I further add a dummy for having worked in a blue-collar job during the first pregnancy.

Summary Statistics. Table (1) presents the descriptive statistics for the full matched and eligible sample. While column (1) describes the full sample, columns (2)-(4) restrict the sample to second-born children with older siblings born in the vicinity of the policy reform thresholds. ${ }^{14}$ When compared to the full sample, second born with older siblings born around a policy reform are less likely to be born preterm and with low birth weight.

\footnotetext{
${ }^{12}$ Both thresholds of weight (low birth weight) and gestational age (preterm) are defined by the World Health Organization.

${ }^{13}$ Following Danzer et al. (2017), I construct this indicator variable by defining all mothers as low SES who completed compulsory schooling or who completed apprenticeship training or intermediate vocational school and additionally have low wages. For the assignment to high and low wage, I use average wage data in the two years prior to a mother's first birth. I classify a women as low wage if her wage is below or equal to the median wage in that specific birth year for all women in my sample. Mothers who have completed at least high school or who finished apprenticeship training or intermediate vocational school and earn a high wage are defined as high-SES mothers.

${ }^{14}$ The chosen bandwidth in my baseline analysis is 24 months pre- and post-policy reform.
} 
Their mothers are more likely to be married and older, as expected. Therefore, as I will focus on higher-order born children who are potentially affected by their mother's longer (or shorter) parental leave stay with the first-born child, the sample will be slightly positively selected with respect to newborn health. However, as 78 percent of Austrian families have more than one child in my sample, this implies that my analysis is based on a non-negligible fraction of births.

In the restricted samples (columns (2)-(4)), the average birth weight ranges from 3,381-3,419 grams and the average gestational length is around 39.7 weeks. The average occurrence of a low birth weight birth is between 3.2-3.3 percent and the one of a preterm birth 3.2-3.6 percent. The 1 minute Apgar scores vary between 8.7-8.9 and 95.8-97.5 percent of the newborns have a healthy Apgar score above 7. Most of the mothers are married (0.72-0.80) and give birth to their second child between the ages of 25-29 (0.38-0.45). On average, about 60 percent of the mothers work during pregnancy with their second child and spend 63-69 days at work.

\section{Empirical design}

This paper focuses on identifying the causal effect of working during pregnancy on newborn health. Specifically, consider the following baseline model:

$$
Y_{i}=\beta_{0}+\beta_{1} \text { work }_{i}^{m}+\beta_{2} X_{i}^{c}+\beta_{3} X_{i}^{m}+\tau_{t}+\epsilon_{i}
$$

where for each individual $i, Y_{i}$ is the outcome of interest. $w_{o r k}^{m}$ represents a dummy for the work status of the mother during pregnancy or the days worked. $X_{i}^{c}$ controls for the child's gender. The vector $X_{i}^{m}$ of maternal characteristics includes controls for 5-year age brackets, marital status, origin, and low SES. $\tau_{t}$ is a vector controlling for year of birth and month of birth fixed effects and $\epsilon_{i}$ is an error term. $\beta_{1}$ is the coefficient of interest corresponding to the effect of prenatal employment on newborn health.

One issue with estimating Equation (1) is omitted variable bias. One such example is the mother's own health status. A mother might choose not to work because she is in bad 
health, which also directly influences the health of her own child. Other unobserved variables that could threaten the validity of a standard ordinary least squares (OLS) approach, are, for example, income and stress.

Regression Discontinuity Design ( $R D D)$. To overcome the issue of omitted variable bias, I base my analysis on the described reforms of the parental leave system that generate quasi-experimental variation in the likelihood of mothers working during pregnancy. More specifically, I use three separate regression discontinuities for the three reforms in July 1990, July 1996, and July 2000. The RDD method and its use in economics is extensively summarized by Imbens and Lemieux (2008) and Lee and Lemieux (2010). It is based on the intuition that all mothers giving birth to their first child just before or just after a policy change do not differ discontinuously in their characteristics, but rather, face two different policies that discontinuously affect a mother's prenatal employment status.

To see this better, imagine two mothers, Mother A and Mother B. Mother A gives birth to her first child in June 1990 and can stay on parental leave up to the first birthday of her child. She has to conceive her second baby by December 1990. If she meets this time window, she does not have to go back to work during the pregnancy with her second child. Mother B gives birth to her first child in July 1990, only one month later than Mother A. She can stay on parental leave for two years and must conceive by January 1992 in order to be exempt from the work requirement. Mother A and Mother B are unlikely to differ in characteristics ex ante. However, Mother B is much more likely to give birth to another child within the grace period. This discontinuity in the likelihood of working during pregnancy with the consecutive child stemming from an exogenous policy reform will be exploited in the following estimation.

Estimation. Following Jacob et al. (2012) and Lee and Lemieux (2010), I estimate local linear regressions in samples around the cutoffs. I estimate separate OLS regressions with a rectangular kernel for each cutoff date and choose in my context a meaningful bandwidth of 24 months. Following Lee and Lemieux (2010), the choice of kernel typically has little impact in practice. I also conduct a sensitivity analysis with different bandwidths chosen 
by the method of Imbens and Kalyanaraman (2012) or Calonico et al. (2016). ${ }^{15}$ I report graphical evidence of the robustness to different bandwidths in the Appendix.

I start by documenting the discontinuity of prolonged parental leave on prenatal employment for mothers having a second child. I estimate the following first-stage regression:

$$
\text { work }_{i}^{m}=\gamma_{0}+\gamma_{1} T_{i}+\gamma_{2} R_{i}+\gamma_{3} T_{i} * R_{i}+v_{i}
$$

The variable $T_{i}$ describes an indicator variable for having an older sibling being born in the post-policy reform period. $R_{i}$ is the rating variable, which indicates the number of months from the older sibling's birth date to the date of policy change, and $v_{i}$ is an idiosyncratic error term. The parameter of interest in Equation (2) is $\gamma_{1} \cdot \gamma_{1}$ describes the size of the change in the outcome work $_{i}^{m}$ at the date of the policy reforms and therefore highlights the discontinuity in the share of mothers working during pregnancy with their second child.

In a second step, I examine the effect of the policy reform on newborn health using the following reduced form equation:

$$
Y_{i}=\delta_{0}+\delta_{1} T_{i}+\delta_{2} R_{i}+\delta_{3} T_{i} * R_{i}+\nu_{i}
$$

This reduced form equation provides estimates of the net effect of parental leave reforms on newborn health.

Identification. The identifying assumptions for inference using the RDD are: (1) the probability of being treated must be discontinuous at the cutoff, and (2) there should be no discontinuity in potential outcomes at the cutoff (Lee and Lemieux, 2010). The second statement requires that no observable nor unobservable factors exhibit any discontinuities at the cutoffs. This is likely fulfilled if there is no precise manipulation on either side of the cutoff.

While assumption (1) holds by construction of the policy reform, assumption (2) cannot

\footnotetext{
${ }^{15}$ The bandwidth selection according to Imbens and Kalyanaraman (2012) is implemented in Stata by the command rdcv and choosing ik as method. The bandwidth selection according to Calonico et al. (2016) is implemented in Stata by the command rdbwselect and choosing the default method mserd.
} 
be directly validated. However, I can conduct standard tests for asserting the validity of assumption (2). The timing of the policy announcement guarantees that individuals cannot perfectly sort at the policy reform threshold. As described by Lalive and Zweimüller (2009), the policy reform in 1990, for example, was only announced three months before implementation and therefore made perfect birth planning impossible. However, pregnant mothers could still influence the timing of a birth via a Caesarean section within a short time window, which I will address in the robustness analysis.

Additionally, to asses credibility of assumption (2) based on observables, I visualize the relationship between the covariates and the rating variable as reported in Figure (A2). In the context of possible confounders, these variables should evolve smoothly across the cutoff. Furthermore, I also report a Covariate Balance Test (see Table (A1)), where I test for discontinuities in my observable variables using regressions outcomes. Across all these tests, the smoothness of predetermined observable maternal characteristics is fulfilled. ${ }^{16}$

Sample Selection. Although the regression discontinuity design likely circumvents the problem of omitted variables bias described above, it does not solve the problem of sample selection. Sample selection in this context can arise as only newborn health measures become observable for those women who choose to become mothers. If the policy changes regarding the duration of paid parental leave directly affect fertility decisions, this might influence the sample of mothers for which the newborn's health is observed. In their analysis, Lalive and Zweimüller (2009) and Lalive et al. (2013) show direct fertility effects of the 1990 policy reform, but no such effects for the other two reforms, in 1996 and $2000 .{ }^{17}$ In order to address the issue of sample selection in the 1990 reform, I follow the approach described by Kim (2016) and Dong (2017) in a robustness analysis to support the causal interpretation of prenatal employment and not only the net effect of the policy reform.

The approach is based on estimating treatment bounds in the presence of sample se-

\footnotetext{
${ }^{16}$ The covariate balance test for the effect on being married reports a significant reduction on being married after the 2000 reform. However, in terms of magnitude this effect is relatively small.

${ }^{17}$ I re-estimate the fertility effect for the 1990 reform with my own sample and find that the policy leads to 2.5 additional children per 100 women within three years. With an estimated first-stage effect size of 19.1 women per 100 women who additionally do not work after the change in the policy, the effect of the sample selection seems relatively small.
} 
lection, leaving the formal specification in Equations (2) and (3) unchanged. Compared to other approaches that deal with sample selection, the chosen one does not require specifying any selection mechanism nor any exclusion restrictions. The only additional assumption for identification is (3) monotonicity, which implies that observability of outcomes is only affected in one direction due to treatment assignment. In the described context, this means that all mothers who gave birth to an additional child in the less-generous parental leave period (before July 1990) would also give birth under the new rules. After the policy reform, additional mothers join the sample who are only induced to give birth to another child under the more generous policy scheme. Monotonicity would be violated if there are mothers who would only give birth to an additional child in the less-generous pre-reform policy period. Here, the assumption of monotonocity is reasonable as mothers who give birth after the policy reform could still go back to work after 1 year and face the same opportunities as pre-policy reform.

The treatment bounds are intended to estimate the share of additional mothers in the after-reform sample ( $\sim 5$ percent). These are the marginal mothers who were induced to have a second child by the reform. Their newborns' outcomes are observable after the reform but not before. In terms of outcomes, these newborns cannot be distinguished from the control group. Therefore, without invoking any additional assumptions, one can assume the extreme situation. In this extreme situation, I restrict the sample to a very favorable group (excluding the lower 5 percent in the respective outcome distribution) and a very unfavourable group (excluding the upper 5 percent in the respective outcome distribution). This provides me with a lower and an upper bound. ${ }^{18}$

\section{Results}

This section starts by discussing the OLS effects of working during pregnancy on newborn health. I will then show, graphically and empirically, RDD estimates of the effects of changing PL duration on maternal employment during pregnancy with her second child and newborn health. I end by reporting several sensitivity analyses in order to test for robustness.

\footnotetext{
${ }^{18}$ Standard erros in this approach are calculated via bootstrapping.
} 


\subsection{Baseline OLS estimates}

Table (2) presents baseline OLS results for estimates of Equation (1). All columns are estimated on the pooled sample of the three RDD 24-months-bandwidth samples with secondborn children. Columns (1) and (3) include only child-level characteristics such as a gender dummy, year, and month of birth fixed effects. In columns (2) and (4), referred to as the full control model, I additionally control for mother-level characteristics: 5-year age dummies, ${ }^{19}$ an indicator of foreign origin, a dummy for the marital status, and a dummy for low SES.

Table (2) is split into Panel A, the extensive margin effect of the work status on newborn health, and Panel B, the intensive margin effect of days worked on newborn health. Both a mother's work status and the days worked during pregnancy are positively related to newborn health outcome measures. The full control model suggests that children of mothers who work during pregnancy are, at the mean, 6.3 percent less likely to be born preterm and 7.0 percent less likely to be of low birth weight, respectively. ${ }^{20}$ The effect sizes are slightly bigger in the full control model for the effect of days worked. A baby of a mother who works 65 days (the average of the three RDD samples) versus that of a mother who does not work at all, is on average 19.4 percent less likely to be born preterm and 19.9 percent less likely to be of low birth weight, all else being equal. Estimates on the two continuous outcome variables of birth weight and gestational length and those for the 1 minute Apgar score and the healthy Apgar score dummy are reported in Tables (3)-(4). Both show the same direction of correlations, while the ones with the Apgar scores are relatively weak.

The sickness dummy is negatively correlated with all newborn health measures, as reported in Panels A and B in Table (2). The full control model shows that being sick leads at the mean to an increase of 91.0-93.4 percent and 91.1-93.3 percent in preterm birth and low birth weight, respectively. To give some idea of the magnitude of this effect, I can compare this finding with Wüst (2015). She reports an increase in preterm birth of roughly 43 percent at the mean if the mother reports being sick during pregnancy. ${ }^{21}$

\footnotetext{
${ }^{19} \mathrm{I}$ also test for other specifications of the age variable commonly used in the literature, such as age and age squared. My main coefficients of interest are, however, unaffected.

${ }^{20}$ The percent terms are evaluated at the mean of the dependent variable, i.e. for the outcome variable preterm: $(0.0335-0.0021) / 0.0335-1=-0.063$.

${ }^{21}$ However, Wüst (2015) estimates this effect on the full sample. If I re-run the OLS regression on my full sample as described in Table (1) Column (1) including all parities and not only second born, I get an increase
} 
Controlling for mother's characteristics only marginally affects the size of the coefficients of interest. ${ }^{22}$ However, controlling for a broad set of observables is not sufficient to rule out endogeneity concerns. Therefore, I will exploit the policy reforms in the next sections in a regression discontinuity set-up to infer the impact of prenatal employment on newborn health.

\subsection{First-stage estimates}

Graphical evidence. In this section, I test the first stage described in Equation (2). In particular, I focus on the extensions of parental leave for the first child and the impact on mothers' employment status during pregnancy with her second child. Figure (3) graphically represents the results. Dots refer to monthly averages, to which linearly fitted values and 95 percent confidence intervals are added. There are statistically significant and economically meaningful discontinuities in the direction as expected around the cutoff dates. The 1990 reform, for example, leads to an approximate decline of 19 percentage points in the share of mothers employed during pregnancy with the second child giving birth to their first child right after July 1990 compared to mothers that gave birth just before the policy reform. The discontinuities for the reforms in 1996 and 2000 highlight the same pattern. When parental leave for the first child declines, as in 1996, the share of mothers employed during pregnancy with their second child increases by approximately 7 percentage points; it declines by 6 percentage points with the extension of parental leave in the year 2000. The intensive margin of days worked corroborates these patterns, where for example in 1990, a 14 percent drop of a potential total of 160 days worked resulted in 22 fewer days worked. ${ }^{23}$

Estimation results. Table (5) presents regression estimates of Equation (2). Each regression is estimated with a chosen bandwidth of 24 months. Columns (1), (3), and (5) show regression results, while columns (2), (4), and (6) add mother's characteristics as controls. All estimates corroborate the graphical evidence found in Figure (3) and confirm the statis-

of 46-52 percent in a preterm birth if a mother is sick, which is comparable in size to the one reported by Wüst (2015).

${ }^{22}$ Table (A2) reports the entire set of coefficients for mother characteristics.

${ }^{23}$ The 160 days are the product of mothers working 32 weeks during pregnancy times 5 days per week. The 32 weeks are the result of an average pregnancy lasting 40 weeks minus 8 weeks mothers have to spend on maternity leave. 
tical significance of the discontinuities in mother's work behavior at the cutoff. In terms of magnitude, the 1990 reform has the strongest impact in the full control model on maternal employment during pregnancy with her second child, decreasing the percentage of mothers employed and the days employed by 19.1 percentage points and 23.0 days, respectively. The corresponding numbers for the 1996 reform show an increase of 7.2 percentage points and 9.5 days in the employment share and days worked. The 2000 reform leads to a decline of 6.4 percentage points in the percentage of mothers working and a decline of 6.6 days in the days worked. Altogether, the documented effects are significant, precisely estimated, and economically important.

The point estimates of the effect of having an older sibling being born post-policy reform on the work status and the days worked do not vary with the inclusion of predetermined mother's controls. This robustness to the inclusion of additional controls confirms the validity of the RDD in this setting. Furthermore, the regression results are also robust to other choices of bandwidths (see Figure (A3)) and functional forms (see Table (A3)).

\subsection{Reduced-form estimates}

Graphical evidence. This section reports the reduced-form estimates of Equation (3). In particular, I analyze the impact of the extension of parental leave for the first child on several health outcomes for the newborn child, such as being born preterm or with low birth weight. These reduced-form estimates can be interpreted as the net effect of the policy reforms on newborn health. As the first-stage estimates were generally large and statistically significant, we would expect to see sizeable effects on newborn health if there is a relationship between the latter and a mother's work status.

Figure (4) shows the effects of the policy changes on newborn health. Dots represent monthly averages and solid lines correspond to values from a linear fit. There is no significant discontinuity visible. This holds true for any of the outcome variables and also for all three policy reforms. Linking these results with the discontinuous jump found for the first-stage

results of prenatal employment leads to the conclusion that my estimates are consistent with a null hypothesis of no effect of maternal employment during pregnancy on newborn health.

Estimation results. The graphical results are complemented with regression outputs 
estimating Equation (3) in Table (6). All columns include a gender dummy, year of birth and month of birth fixed effects. Columns (1), (3), and (5) show regression results with childlevel controls only, while columns (2), (4), and (6) add mother's characteristics controls. All estimates support the graphical evidence found in Figure (4). For all three reforms and all newborn health outcomes, I document statistically insignificant and generally small effects. For example in 1990, the estimates allow me to rule out an increase of more than 0.6 percentage points and a decline of more than 0.2 percentage points in the probability of being born with low birth weight. ${ }^{24}$ Furthermore, the point estimates are not affected by the inclusion of mother's characteristics controls. Overall, these results indicate that the net impact of the extension of parental leave duration for the first child and the accompanying significant reduction in prenatal employment during pregnancy with the second child on newborn health is negligible.

\subsection{Robustness tests}

In this section, I test the robustness of my results. For most of the reported results, I will only focus on the 1990 reform because all conclusions hold true for the other reforms.

Alternative outcome measures. Figure (5) reports results on additional outcome measures such as birth weight, gestational length, 1 min Apgar score, and a dummy for a healthy Apgar score. As with the two main outcome measures discussed so far, there are no visible discontinuities around the thresholds. This is convincing that there is no effect of the reform on any newborn health measure. While preterm and low birth weight dummies might capture effects on very vulnerable newborns, the continuous variables of birth weight and gestational age and Apgar scores measure potentially another dimension of newborn health.

Different birth weight and gestational age thresholds. In Figure (A4), I report the reducedform effect for separate regressions with different choices of birth weight and gestational age cutoffs. While low birth weight, defined as less than 2,500 grams, and being born preterm, defined as less than 37 weeks of gestational age, are relatively arbitrary cutoffs, I show that the results are robust to different choices for these outcome variables. No matter what birth

\footnotetext{
${ }^{24}$ This is the result of a 95 percent confidence interval, leading to a positive effect of a maximum of +0.006 $(=0.002+1.96 * 0.002)$ and a minimum of $-0.002(=0.002-1.96 * 0.002)$.
} 
weight and gestational age threshold is chosen, the effect of the policy reforms on these birth outcomes is statistically insignificant.

Donut estimations. Panel A of Table (7) shows results of Donut estimations, which create a hole in the middle of the sample. Here I exclude data points from second borns with older siblings born within a week on both sides of the cutoff. As all policy reforms were announced only shortly before the actual implementation, selection into motherhood and therefore a perfect planning of birth into a specific policy regime can be ruled out. However, the choice of a Caesarean section and therefore timing the birth might still be possible up to a short time window of around 1 week. Lalive and Zweimüller (2009) investigate the issue of this narrow-window timing and argue that although there is a steady increase in births on a day-to-day basis from June to July, there is no discontinuity in the reported births on July 1. Also in my analysis, results are robust to this adjustment and all conclusions hold true.

Adding third born. In Panel B of Table (7), I add the sample of third born with an older sibling born 24 months around the cutoff of a policy reform. Although the sample size and therefore the precision increase, Panel B detects no major changes to the previous conclusions. Mothers are significantly less likely to work during pregnancy with their higherorder child if facing longer parental leave with their older child. Effects on newborn health measures for their consecutive child are still not significant. This highlights that the results are not specific only to second borns.

Sample selection. Panel C of Table (7) addresses the previously raised concern of selection into second motherhood by reporting bounds on treatment effects in the presence of possible selection. Applying the monotonicity assumption for the 1990 reform yields the bounds reported in Panel $\mathrm{C}$ in Table (7), where I draw the same conclusions as before. Maternal employment during pregnancy with the second child decreases significantly with no significant effects on newborn health for the second child.

Placebo reform 1988. In Panel D of Table (7), I show estimation results of a placebo regression assuming a policy reform in July 1988. As expected, this placebo treatment in a non reform year shows no significant effects for any of the outcome variables. Interestingly, as this is known to be a true zero effect, I can compare the standard errors of this specification with the results reported for the three reforms in Table (6). The size of the standard errors 
of the two outcome measures is very similar for the placebo and the reform regressions.

\section{Discussion}

Heterogeneity. I stratify my sample according to several different maternal characteristics. ${ }^{25}$ I start by analyzing broad subsamples in which I classify mothers into blue versus white collar, low versus high socioeconomic status, and married versus unmarried. Several considerations give rise to these broad classifications. Stratification by occupational collar, for example, allows me to differentiate between manual labor versus office work due to its correlation with job task. A priori, it is not clear whether one would expect more beneficial effects for one or the other, as different types of job tasks could have varying effects over the pregnancy cycle. Socioeconomic status considers general differences in which potentially both low- and high-SES mothers benefit from the parental leave policy. Job protection might favor high SES mothers where her skills are more attached to her current job, while paid leave might be more beneficial for low-SES mothers. Finally, one might expect married mothers to react stronger in decreasing prenatal employment due to longer leave, as they are in a stable family environment and thus are more likely to plan subsequent fertility.

Results for these subgroups are reported in Figure (6) and are in line with expectations. There are differences across subgroups with respect to prenatal maternal employment; however, except for married versus unmarried mothers, these are not large and the effect for each subgroup per se is sizeable and significantly different from zero. Unlike prenatal employment, the general finding for newborn health measures across all reported subgroups is not statistically different from zero. Standard erros become larger for smaller subgroups (such as unmarried mothers for example), but all estimates are relatively small in absolute terms. The only difference occurs across socioeconomic status where there is a sign switch for the effect of reduced prenatal employment on the likelihood of a preterm birth. However, as both effects are still indistinguishable from zero, in a next step, I refine mothers by income quintiles.

\footnotetext{
${ }^{25}$ Information about mother's characteristics refer to the first pregnancy to mitigate possible endogeneity concerns.
} 
Results for mothers by income quintiles are reported in Figure (7). Interestingly, the results by socioeconomic status, which were insignificant but of opposing sign, become statistically significant despite smaller sample groups. All mothers are less likely to work during pregnancy after the 1990 reform and show sizeable reductions in prenatal employment from 12.9-21.3 percentage points. The reduction in prenatal employment leads to better outcomes for their newborns (i.e. a reduction in preterm births by 1.3 percentage points) for mothers in the lowest income quintile and to worse outcomes for their newborns (i.e. an increase in preterm births by 1.4 percentage points) for mothers in the highest income quintile. These results can be explained by income effects during pregnancy. The parental leave policy is designed as flat benefit, which describes an income improvement for some mothers and an income decline for others. The increase in income for low-income mothers and the reduction in preterm births is in line with previous literature (Hoynes et al., 2015; Almond et al., 2011; Barber and Gertler, 2008; Amarante et al., 2016). More interestingly, and also substantially less studied in the literature, is the harmful effect on newborn health of decreasing income for high-income mothers.

While the stratification by income quintile hints toward an income effect, the effect cannot be explained by differential occupational exposures. ${ }^{26} \mathrm{I}$ also conduct subgroup analysis by industry and find no significant effects on newborn health measures. This is interesting as one might expect different types of occupations to expose mothers to different types of risky behavior during pregnancy, as for example, smoking in the hospitality industry or diseases in the human health and social work industry.

I also test for other heterogeneous subgroups such as gender of the child, above median age of the mother, country of origin of the mother, and health outcomes of the preceding child (i.e. born with low birth weight). I find a zero effect on all newborn health measures for all of these subgroups.

Age Difference. Although the mean difference in months from the first to second born is not affected by any of the policy reforms, certain specific age windows could be affected by the design of the policy reforms. From a medical point of view, siblings with an age

\footnotetext{
${ }^{26}$ Results are not reported here but are available upon request.
} 
difference of less than 18 months are particularly interesting to look at more closely, as this very short spacing can lead to worse outcomes of the second born (Conde-Agudelo et al., 2006). Therefore, for a better understanding of the age difference between first- and secondborn children, I decompose the effect into respective age categories implied by the three policy reforms. Table (A4) reports the results. An extension of parental leave as in 1990 and 2000 reduces the likelihood of very small age differences, while a reduction in parental leave increases the likelihood of small age differences. The effect is significant for the 1990 and 1996 reforms. Thus, if short spacing would harm the health of the second-born child, this would bias the effect of prenatal maternal employment on newborn health upwards in 1990 and downwards in 1996. However, in terms of magnitude, both effects are small.

\section{Conclusion}

This paper analyzes the effect of maternal employment during pregnancy on newborn health. I use data on all Austrian births and work histories of the respective mothers. To overcome the endogeneity of employment decisions, I exploit three policy reforms regarding the duration of parental leave. I find no evidence that prenatal employment affects any of the outcomes, measured via birth weight, gestational age, and Apgar scores. This stands in contrast to the positive correlation of prenatal employment with newborn health as reported in the OLS regressions.

For the 1990 reform, which extended parental leave from one to two years, I document a significant 19.1 percentage point decline in the share of mothers employed during pregnancy with their second child and insignificant effects for all newborn health measures. Even though prenatal employment varies substantially by subgroups, I find no evidence of an effect on health outcomes at birth even in these subpopulations. The subgroup analysis by income quintiles is the only one to reveal significant effects on newborn health, which can be explained by income effects (i.e. higher income for poorer mothers leads to better newborn health).

This study shows that the net effect of changes in parental leave policies for the second child is insignificant. This result is robust to the inclusion of covariates and several different 
specifications. The zero effect of prenatal employment adds to the scarce and conflicting literature on maternal employment during pregnancy on newborn health. With increasing employment rates for pregnant women, it is crucial to understand the mechanisms of prenatal employment on newborn health.

The literature on the effects of pregnancy conditions on long-term outcomes identifies the second trimester of a pregnancy as the trimester with the strongest neural brain development (Schwandt, 2017; Black et al., 2014). This could mean that the effect of exposure to maternal labor market participation during pregnancy could only be detectable in the long run and may not be visible on the day of birth. As such, linking prenatal employment with long-term outcomes such as educational attainment and labor market participation of the child itself could be explored in future studies.

The findings in this paper should interest policymakers and pregnant women. Unlike post natal child rearing, the duty of pregnancy cannot be shared among partners. However, this should not worry mothers or employers, as there is no evidence that the working status during pregnancy leads to bad health outcomes for the unborn baby. However, the results should also be interpreted within the Austrian context, where women are relatively well protected against hazardous situations at their workplace while pregnant. Furthermore, the results of this paper will help women to optimally allocate the time allowed by parental leave policies. Several countries design their parental leave policies in such a way that women can choose how to divide a certain amount of weeks pre- and post-birth. These results show that women can safely take a majority of their parental leave after giving birth. 


\section{References}

Ahammer, A., Halla, M., and Schneeweis, N. E. (2018). The effect of prenatal maternity leave on short and long-term child outcomes. Technical report, Working Paper.

Aizer, A. (2011). Poverty, Violence, and Health: The Impact of Domestic Violence during Pregnancy on Newborn Health. Journal of Human Resources, 46(3):518-538.

Aizer, A., Stroud, L., and Buka, S. (2015). Maternal Stress and Child Outcomes: Evidence from Siblings. Journal of Human Resources.

Almond, D. (2006). Is the 1918 Influenza Pandemic Over? Long-Term Effects of In Utero Influenza Exposure in the Post-1940 US Population. Journal of Political Economy, 114(4):672-712.

Almond, D. and Currie, J. (2011). Human capital development before age five. Handbook of labor economics, 4:1315-1486.

Almond, D., Currie, J., and Duque, V. (2017). Childhood Circumstances and Adult Outcomes: Act II. Forthcoming in the Journal of Economic Literature.

Almond, D., Hoynes, H. W., and Schanzenbach, D. W. (2011). Inside the War on Poverty: The Impact of Food Stamps on Birth Outcomes. The Review of Economics and Statistics, 93(2):387-403.

Amarante, V., Manacorda, M., Miguel, E., and Vigorito, A. (2016). Do Cash Transfers Improve Birth Outcomes? Evidence from Matched Vital Statistics, Program and Social Security Data. American Economic Journal: Economic Policy, 8(2):1-43.

Baker, M. and Milligan, K. (2008). Maternal employment, breastfeeding, and health: Evidence from maternity leave mandates. Journal of health economics, 27(4):871-887.

Barber, S. L. and Gertler, P. J. (2008). The impact of Mexico's conditional cash transfer programme, Oportunidades, on birthweight. Tropical Medicine $\&$ International Health, 13(11):1405-1414.

Beuchert, L. V., Humlum, M. K., and Vejlin, R. (2016). The length of maternity leave and family health. Labour Economics, 43:55-71.

Black, S. E., Bütikofer, A., Devereux, P. J., and Salvanes, K. G. (2014). This is Only a Test? Long-Run and Intergenerational Impacts of Prenatal Exposure to Radioactive Fallout. National Bureau of Economic Research. 
Black, S. E., Devereux, P. J., and Salvanes, K. G. (2016). Does Grief Transfer across Generations? Bereavements during Pregnancy and Child Outcomes. American Economic Journal: Applied Economics, 8(1):193-223.

Calonico, S., Cattaneo, M. D., Farrell, M. H., and Titiunik, R. (2016). Regression discontinuity designs using covariates. Review of Economics and Statistics, (0).

Camacho, A. (2008). Stress and birth weight: evidence from terrorist attacks. American Economic Review, 98(2):511-15.

Carneiro, P., Løken, K. V., and Salvanes, K. G. (2015). A Flying Start? Maternity Leave Benefits and Long-Run Outcomes of Children. Journal of Political Economy, 123(2):365412.

Conde-Agudelo, A., Rosas-Bermúdez, A., and Kafury-Goeta, A. C. (2006). Birth spacing and risk of adverse perinatal outcomes: a meta-analysis. Jama, 295(15):1809-1823.

Currie, J., Hanushek, E., Kahn, E. M., Neidell, M., and Rivkin, S. (2009). Does Pollution Affect School Absenteeism. Review of Economics and Statistics, 91:682-694.

Currie, J. and Rossin-Slater, M. (2013). Weathering the Storm: Hurricanes and Birth Outcomes. Journal of Health Economics, 32(3):487-503.

Currie, J. and Schwandt, H. (2013). Within-mother analysis of seasonal patterns in health at birth. Proceedings of the National Academy of Sciences, 110(30):12265-12270.

Currie, J. and Schwandt, H. (2016). The 9/11 Dust Cloud and Pregnancy Outcomes: A Reconsideration. Journal of Human Resources, 51(4):805-831.

Dahl, G. B., Løken, K. V., Mogstad, M., and Salvanes, K. V. (2016). What is the case for paid maternity leave? Review of Economics and Statistics, 98(4):655-670.

Danzer, N., Halla, M., Schneeweis, N., and Zweimüller, M. (2017). Parental Leave, (In)Formal Childcare and Long-Term Child Outcomes. Technical report, CESifo Working Paper.

Danzer, N. and Lavy, V. (2018). Paid parental leave and children's schooling outcomes. The Economic Journal, 128(608):81-117.

Dong, Y. (2017). Regression Discontinuity Designs with Sample Selection. Journal of Business $\mathcal{E}$ Economic Statistics. 
Dustmann, C. and Schönberg, U. (2012). Expansions in maternity leave coverage and children's long-term outcomes. American Economic Journal: Applied Economics, 4(3):190224.

Ginja, R., Jans, J., Karimi, A., et al. (2017). Parental investments in early life and child outcomes evidence from swedish parental leave rules. Technical report, Institute for the Study of Labor (IZA).

Heckman, J. J. (2007). The economics, technology, and neuroscience of human capability formation. Proceedings of the national Academy of Sciences, 104(33):13250-13255.

Hoynes, H., Miller, D., and Simon, D. (2015). Income, the Earned Income Tax Credit, and Infant Health. American Economic Journal: Economic Policy, 7(1):172-211.

Imbens, G. and Kalyanaraman, K. (2012). Optimal Bandwidth Choice for the Regression Discontinuity Estimator. The Review of Economic Studies, 79(3):933-959.

Imbens, G. W. and Lemieux, T. (2008). Regression discontinuity designs: A guide to practice. Journal of Econometrics, 142(2):615-635.

Jacob, R., Zhu, P., Somers, M.-A., and Bloom, H. (2012). A Practical Guide to Regression Discontinuity. $M D R C$.

Jurviste, U., Prpic, M., and Sabbati, G. (2016). Maternity and paternity leave in the eu. Technical report, European Parliament.

Kennedy, K. I., Rivera, R., and McNeilly, A. S. (1989). Consensus statement on the use of breastfeeding as a family planning method. Contraception, 39(5):477-496.

Kim, B. M. (2016). Do Developmental Mathematics Develop Mathematics Proficiency? Bounding their Effectiveness in RDD with the Presence of Dropouts. Unpublished.

Lalive, R., Schlosser, A., Steinhauer, A., and Zweimüller, J. (2013). Parental Leave and Mothers' Careers: The Relative Importance of Job Protection and Cash Benefits. The Review of Economic Studies, 81(1):219-265.

Lalive, R. and Zweimüller, J. (2009). How does Parental Leave affect Fertility and Return to Work? Evidence from Two Natural Experiments. The Quarterly Journal of Economics, 124(3):1363-1402.

Lee, C. (2014). Intergenerational health consequences of in utero exposure to maternal stress: Evidence from the 1980 kwangju uprising. Social Science $\&$ Medicine, 119:284-291. 
Lee, D. S. and Lemieux, T. (2010). Regression Discontinuity Designs in Economics. Journal of Economic Literature, 48:281-355.

Olivetti, C. and Petrongolo, B. (2017). The economic consequences of family policies: lessons from a century of legislation in high-income countries. Journal of Economic Perspectives, 31(1):205-30.

Persson, P. and Rossin-Slater, M. (2018). Family Ruptures, Stress, and the Mental Health of the Next Generation. Amercian Economic Review, 108(4-5):1214-1252.

Quintana-Domeque, C. and Ródenas-Serrano, P. (2017). The Hidden Costs of Terrorism: The Effects on Health at Birth. Journal of Health Economics.

Rasmussen, A. W. (2010). Increasing the length of parents' birth-related leave: The effect on children's long-term educational outcomes. Labour Economics, 17(1):91-100.

Rossin, M. (2011). The Effects of Maternity Leave on Children's Birth and Infant Health Outcomes in the United States. Journal of Health Economics, 30(2):221-239.

Rossin-Slater, M. (2017). Maternity and Family Leave Policy. Forthcoming in the Oxford Handbook of Women and the Economy.

Ruhm, C. J. (2000). Parental leave and child health. Journal of health economics, 19(6):931960.

Schwandt, H. (2017). The Lasting Legacy of Seasonal Influenza: In-Utero Exposure and Labor Market Outcomes. IZA Discussion Paper Series.

Stearns, J. (2015). The effects of paid maternity leave: Evidence from temporary disability insurance. Journal of Health Economics, 43:85-102.

Tanaka, S. (2005). Parental leave and child health across oecd countries. The Economic Journal, 115(501).

Wüst, M. (2015). Maternal employment during pregnancy and birth outcomes: Evidence from Danish siblings. Health Economics, 24(6):711-725. 


\section{$9 \quad$ Figures and Tables}

Figure 1: Overview policy changes

\section{Until June 1990: Baseline}

birth latest $\overleftarrow{\text { conception 2nd birth }}$

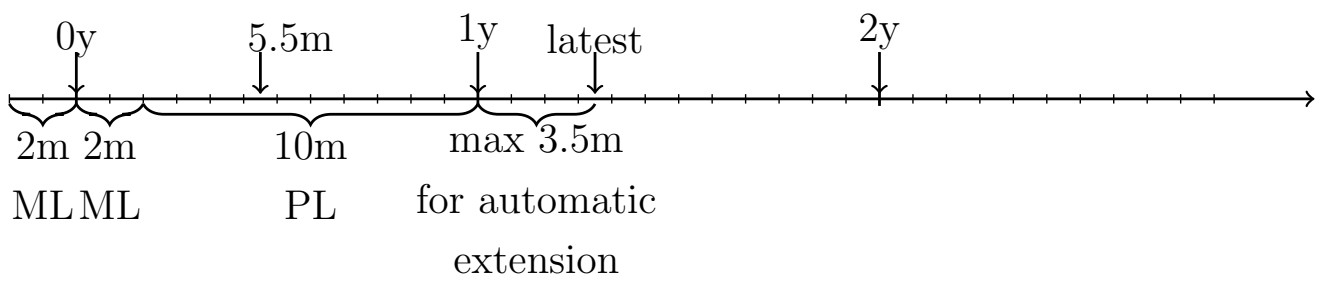

- PL up to age of $12 \mathrm{~m}$ for both duration of cash benefits and job protection

July 1990 - June 1996: Expansion Period I

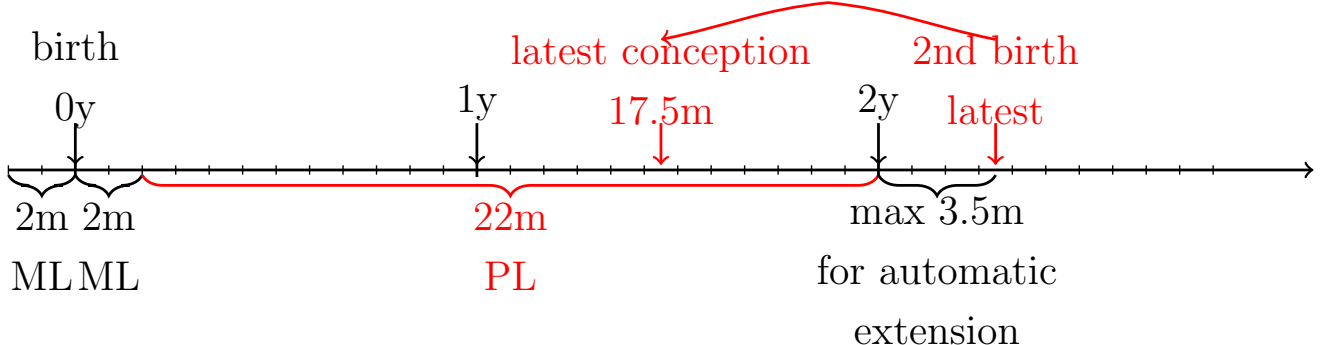

- PL up to age of $24 \mathrm{~m}$ for both duration of cash benefits and job protection

July 1996 - June 2000: Reduction Period I

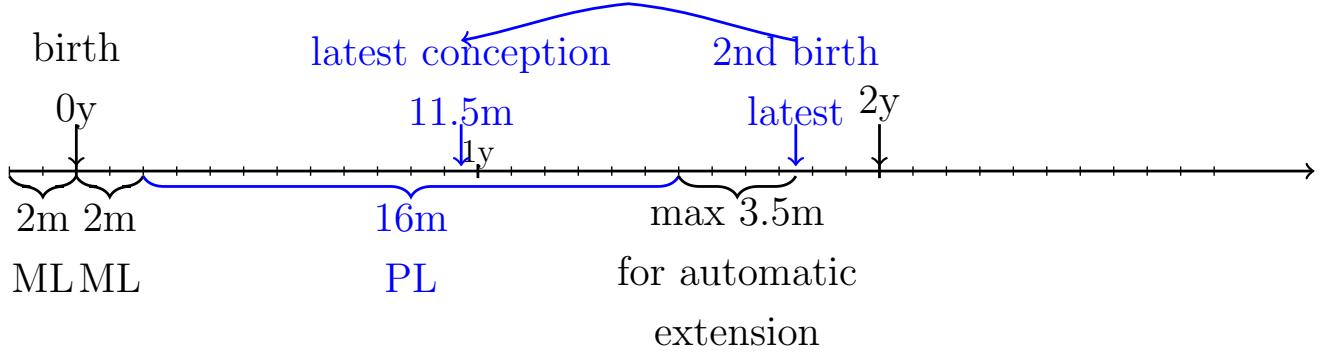

- PL up to age of $18 \mathrm{~m}$ for duration of cash benefits; job protection unchanged (24m)

\section{Post July 2000: Expansion Period II}

birth

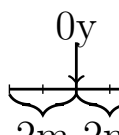

$2 \mathrm{~m} 2 \mathrm{~m}$

ML ML

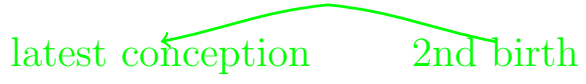

$28 \mathrm{~m}$

PL $\max 3.5 \mathrm{~m}$

for automatic

extension

- PL up to age of $30 \mathrm{~m}$ for duration of cash benefits; job protection unchanged $(24 \mathrm{~m})$ 
Figure 2: Employment status of mothers by week of pregnancy

(a) 1990

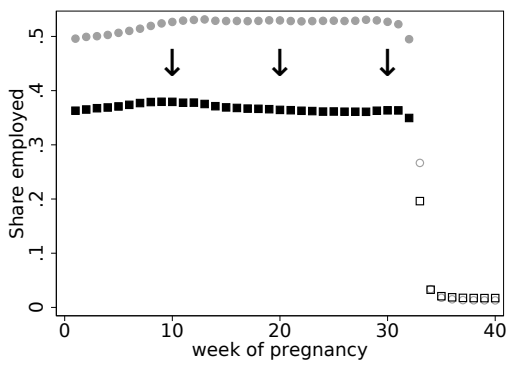

(b) 1996

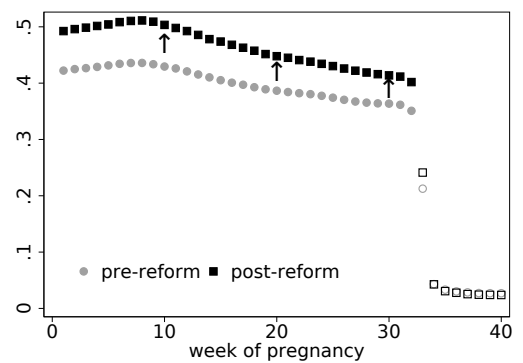

(c) 2000

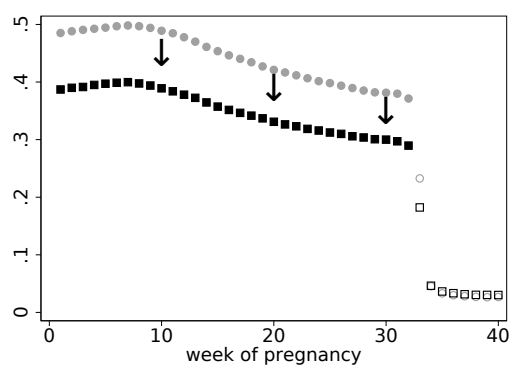

Notes: This Figure reports the share of women who work during pregnancy with their second child. Mothers considered are all women pregnant with their second child who gave birth to their first child 24 months before and after the policy changes in July 1990, July 1996 and July 2000. Hollow squares and circles refer to weeks where mothers are supposed to be on maternity leave (after week 32). The sample consists of all matched and eligible mothers that are still pregnant at a given week of pregnancy (i.e. with preterm births the sample gets smaller moving from week 0 to week 40). 
Figure 3: RDD plots - prenatal employment

Panel A: Share employed during 2nd pregnancy

(a)

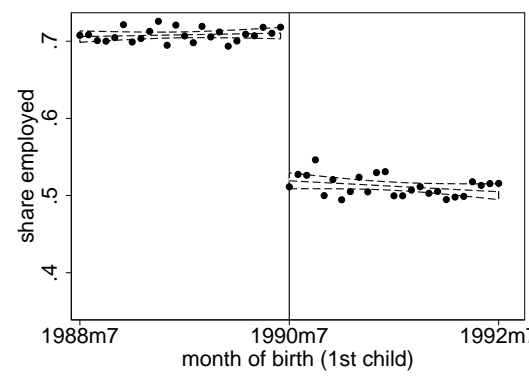

(b)

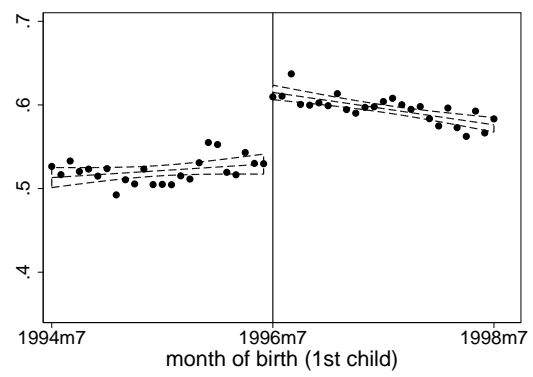

(c)

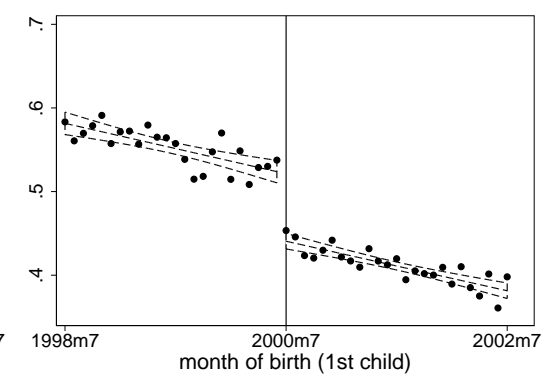

Panel B: Percentage of days employed per 2nd pregnancy

(d)

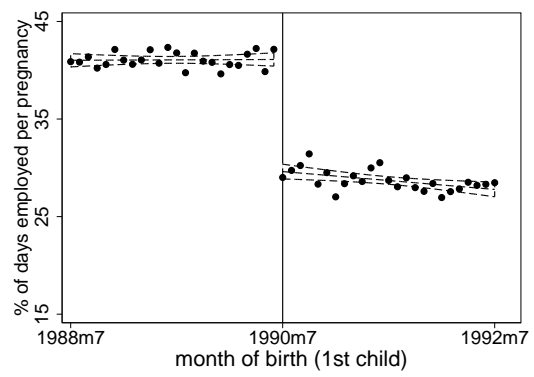

(e)

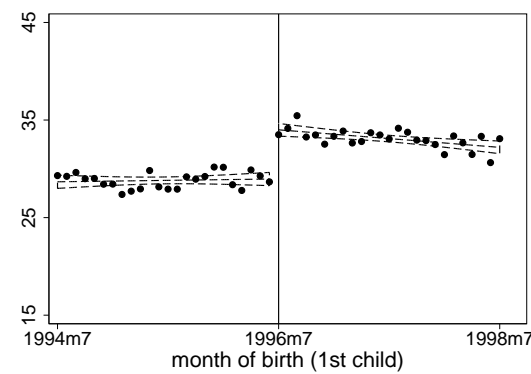

(f)

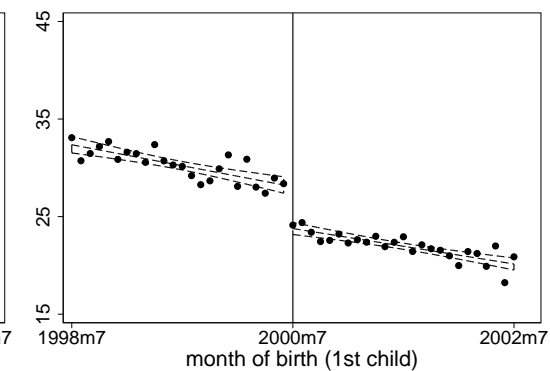

Notes: This Figure reports the fraction of mothers working during pregnancy with their second child and the average percentage of days employed per pregnancy by month of birth of the first child. All subfigures are based on the full sample of matched and eligible mothers that gave birth to their first child not more than 24 months apart from a policy reform. 
Figure 4: RDD plots - newborn health

(a)

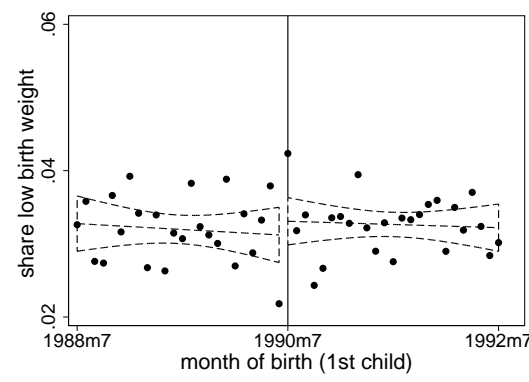

(d)

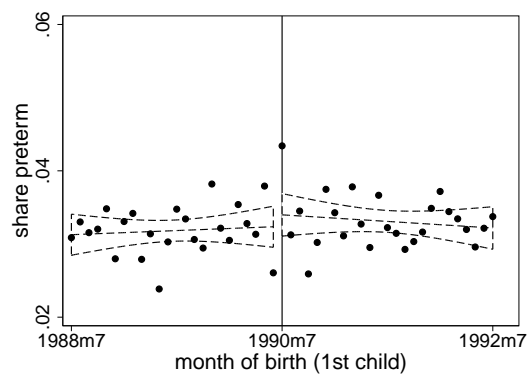

Panel A: Share low birth weight

(b)

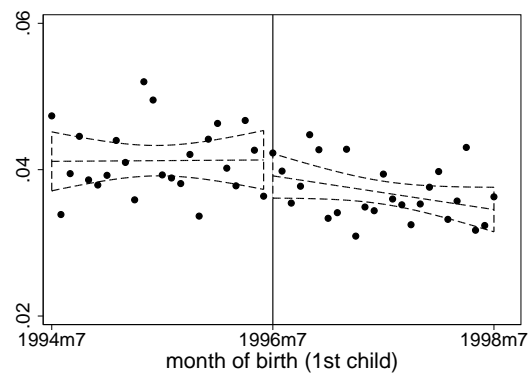

(c)

Panel B: Share preterm

(e)

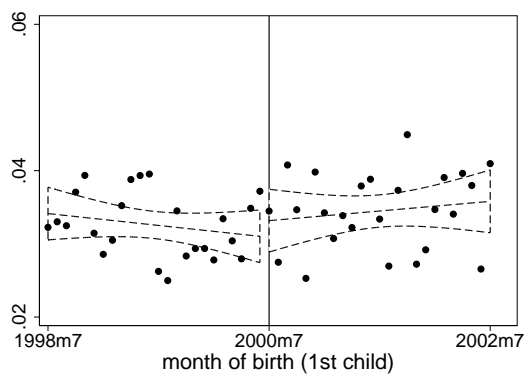

(f)

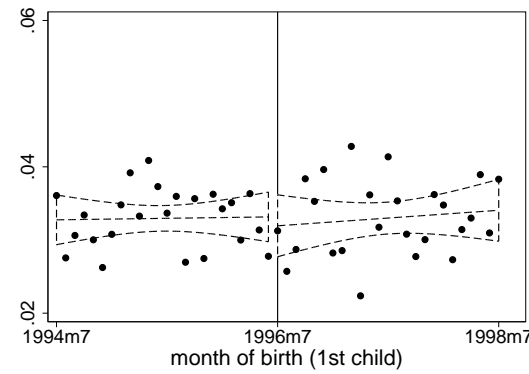

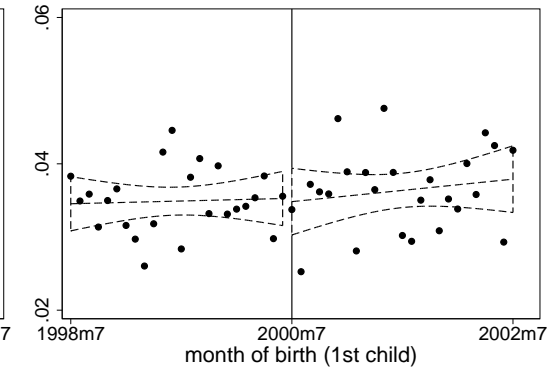

Notes: This Figure reports the average share of second children being born with low birth weight and preterm by month of birth of the first child (their older sibling). Note that I introduce a shifter for subfigure (b). Birth weight has been reported in hectograms up to December 1998. From January 1999 birth weight is measured in decagrams. This switch goes hand in hand with a discontinuous increase in birth weight and decrease in the probability of low birth weight most likely due to a rounding down previous to 1999. I correct for it in these graphs by multiplying birth weight observed after the shift with the change in yearly average values from 1998 to 1999. All subfigures are based on the full sample of matched and eligible mothers that gave birth to their first child not more than 24 months apart from a policy reform. 
Figure 5: RDD plots - newborn health additional outcome measures Panel A: Birth weight

(a)

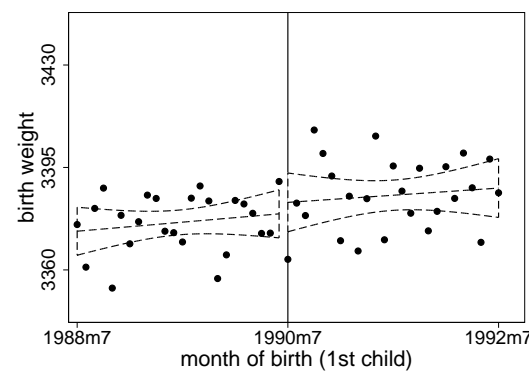

(d)

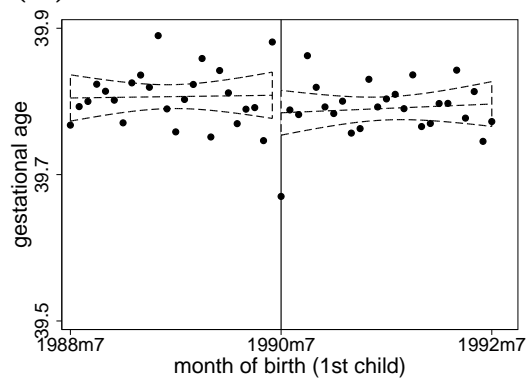

$(\mathrm{g})$

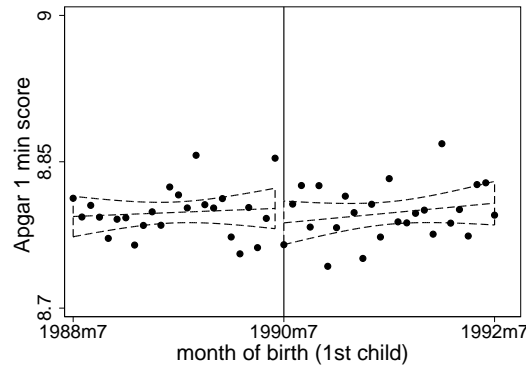

(b)

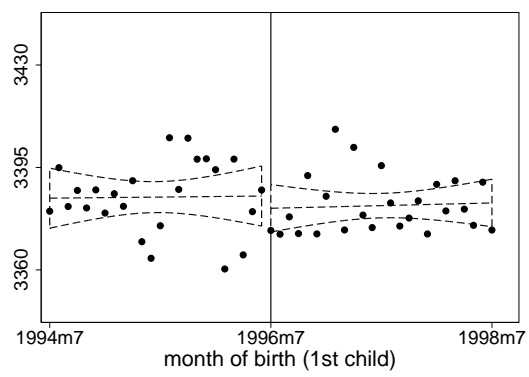

Panel B: Gestational age

(e)

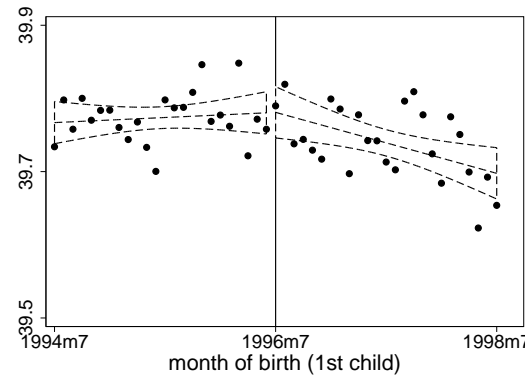

Panel C: Apgar 1 min score

(h)

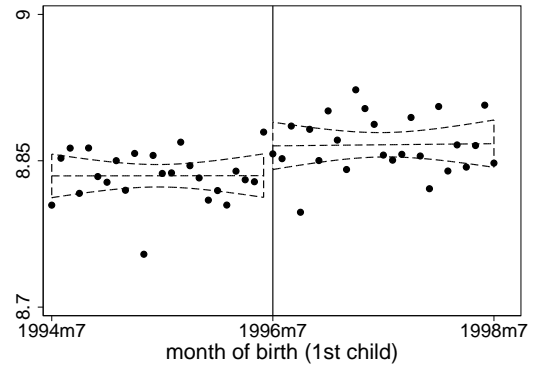

(c)

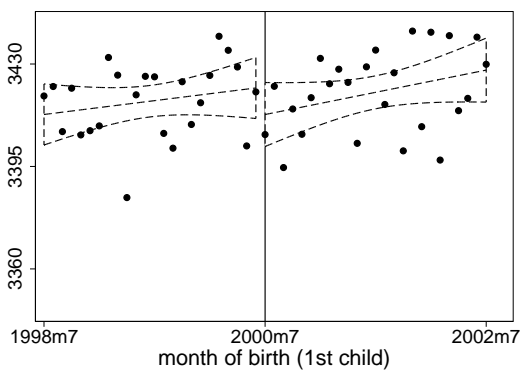

(f)

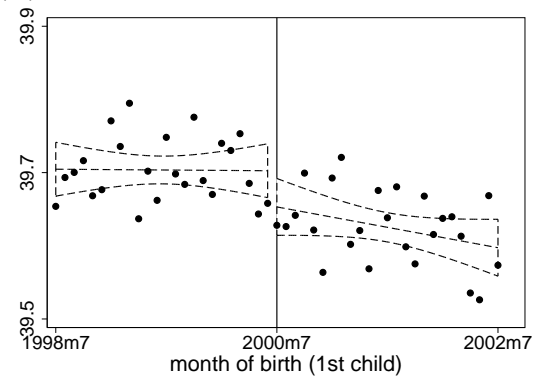

(i)

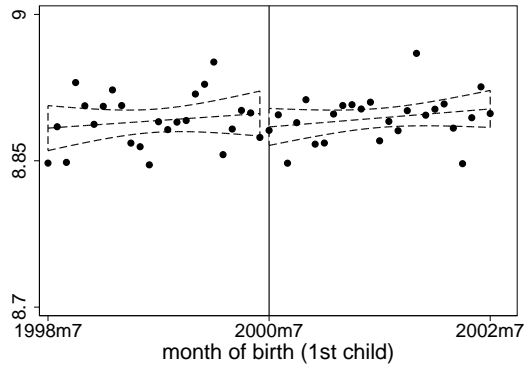

Panel D: Share with healthy Apgar score $(>=7)$

$(\mathrm{j})$

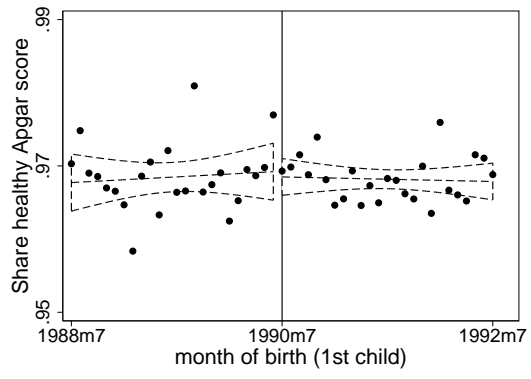

(k)

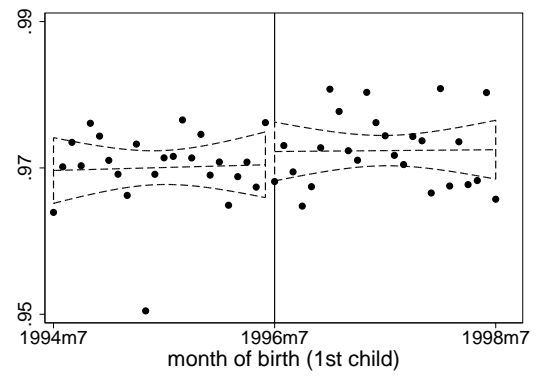

(l)

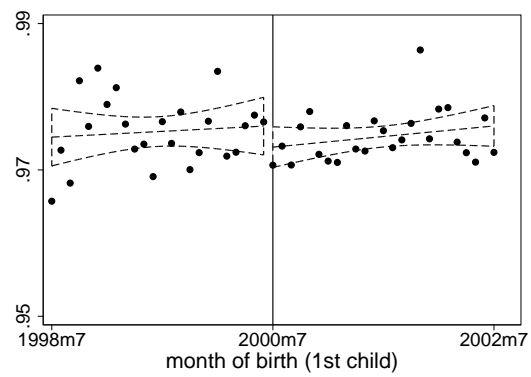

Notes: This Figure reports the average birth weight, gestational age, 1 min Apgar score and the share with a healthy Apgar score $(>=7)$ of second children by month of birth of the first child (their older sibling). Note that I introduce a shifter for the subfigure (b) as outlined in the Notes of Figure (4). All subfigures are based on the full sample of matched and eligible mothers that gave birth to their first child not more than 24 months apart from a policy reform. 
Figure 6: RDD estimates - general heterogeneity

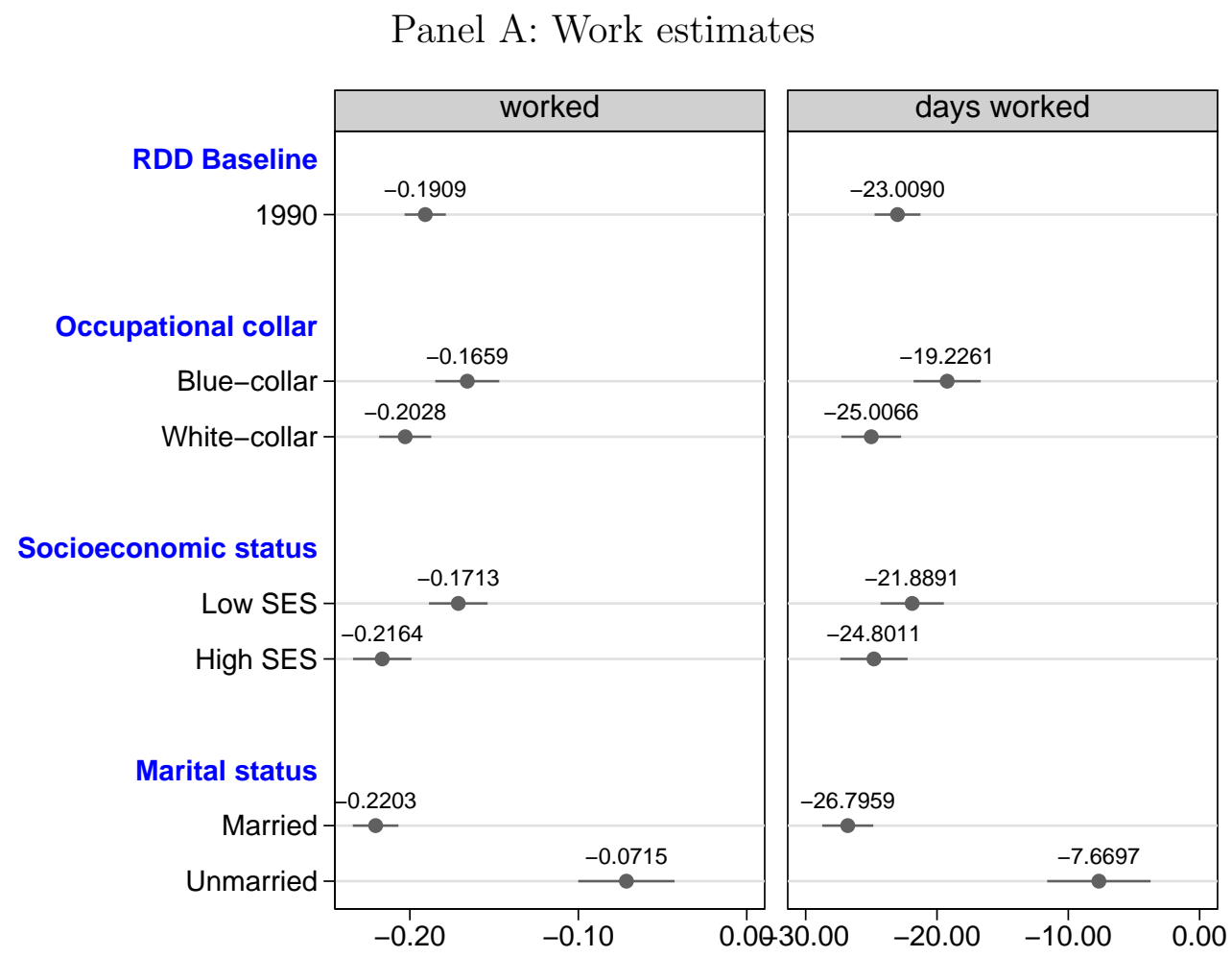

Panel B: Newborn health estimates

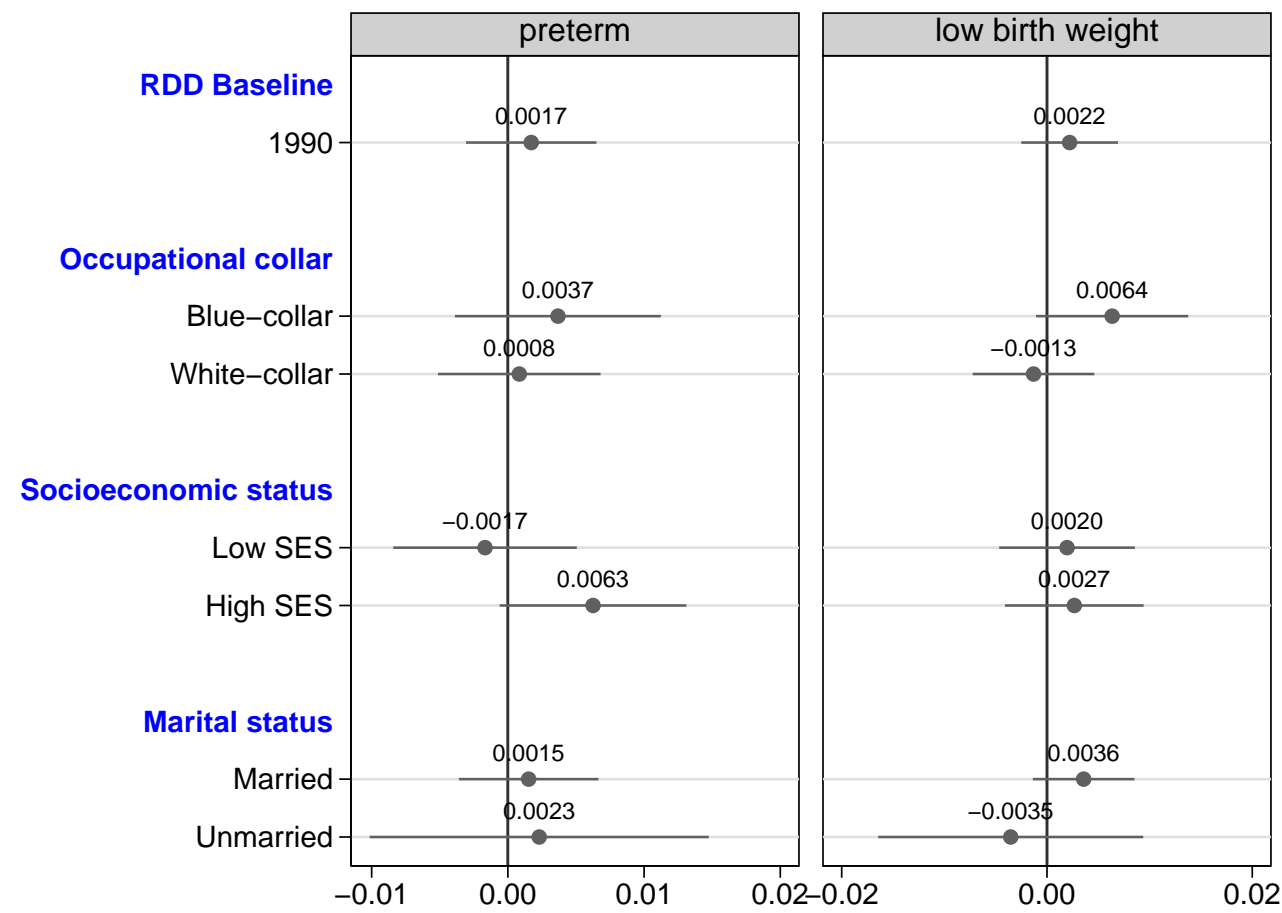

Notes: This Figure reports in Panel A (B) parameter estimates for different specifications for the coefficient $\gamma_{1}\left(\delta_{1}\right)$ of having an older sibling born post policy reform on work status and days worked (low birth weight and preterm). Regression coefficients with a 95 percent confidence interval are displayed. The sample consists of all matched and eligible mothers that gave birth to their first child not more than 24 months apart from the respective policy reform. 
Figure 7: RDD estimates - heterogeneity by income quintiles

Panel A: Work estimates

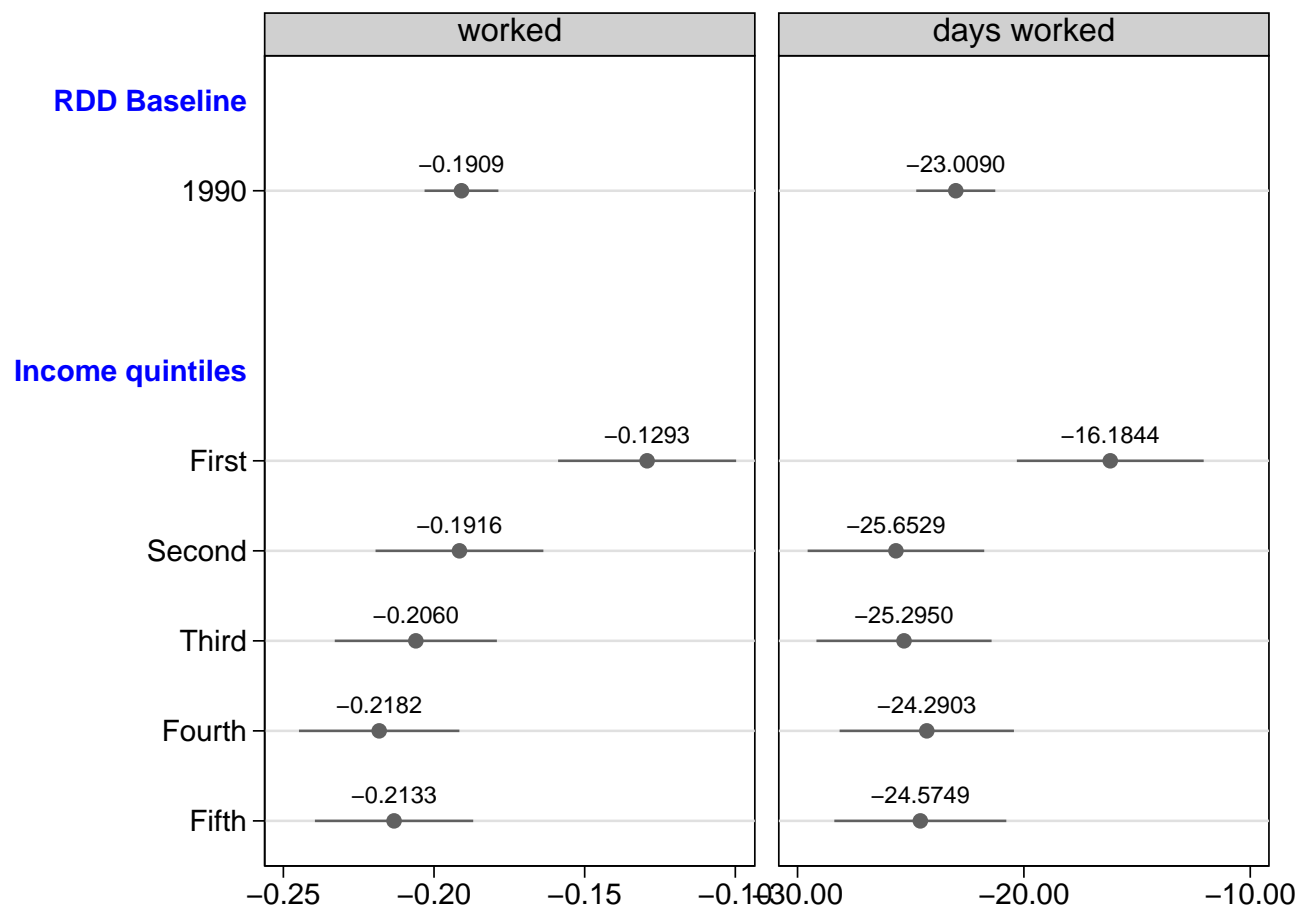

Panel B: Newborn health estimates

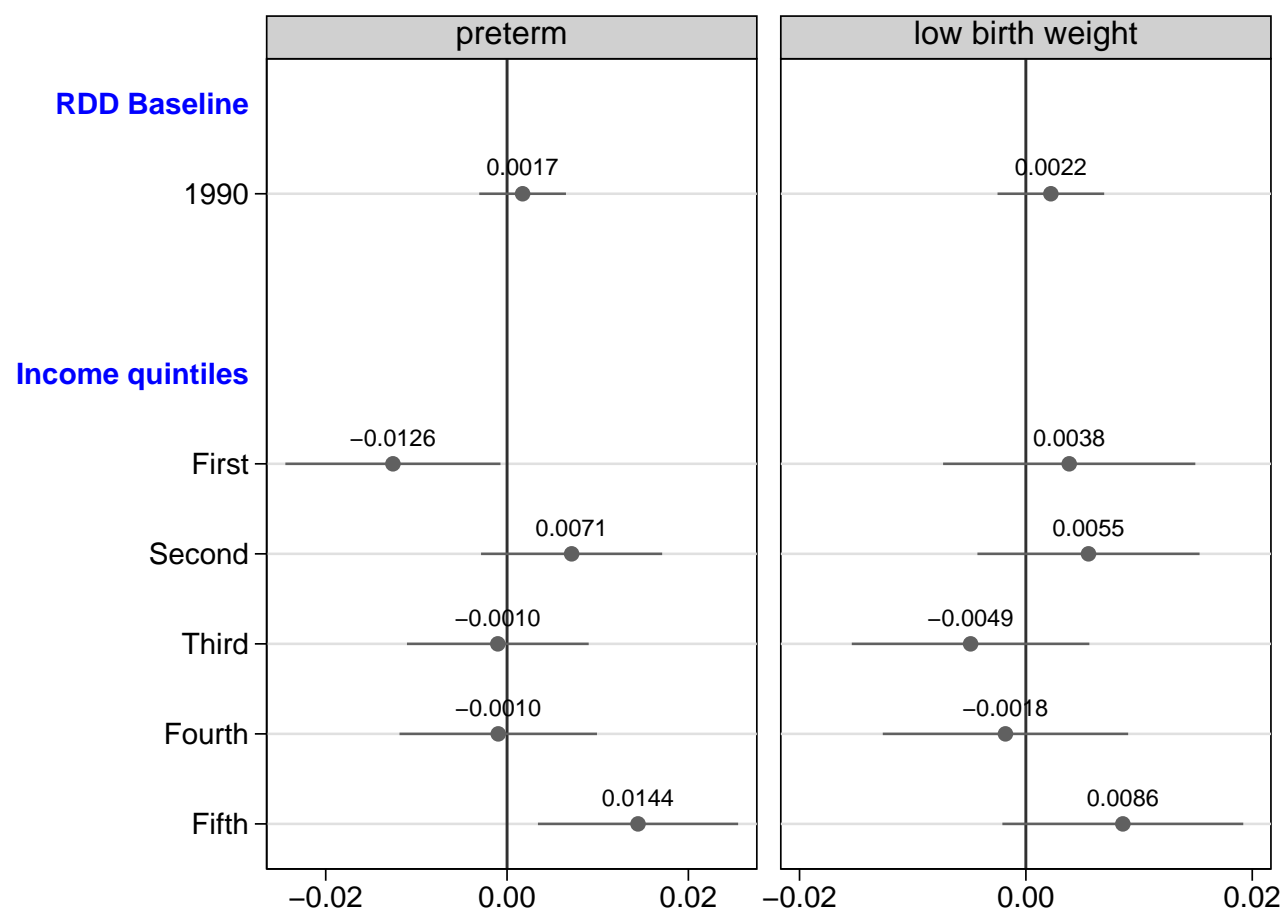

Notes: This Figure reports in Panel A (B) parameter estimates for different specifications for the coefficient $\gamma_{1}\left(\delta_{1}\right)$ of having an older sibling born post policy reform on work status and days worked (low birth weight and preterm). Regression coefficients with a 95 percent confidence interval are displayed. The sample consists of all matched and eligible mothers that gave birth to their first child not more than 24 months apart from the respective policy reform. 
Table 1: Descriptive statistics

\begin{tabular}{lcccc}
\hline \hline & Full sample & 1990 sample & 1996 sample & 2000 sample \\
\hline Birth weight (in gram) & $3,320.028$ & $3,381.319$ & $3,410.534$ & $3,419.033$ \\
& $(519.768)$ & $(500.795)$ & $(505.488)$ & $(503.999)$ \\
Birth length (in cm) & 50.494 & 50.699 & 50.785 & 50.746 \\
& $(2.641)$ & $(2.507)$ & $(2.559)$ & $(2.572)$ \\
Gestational length (in weeks) & 39.686 & 39.797 & 39.757 & 39.665 \\
& $(1.776)$ & $(1.625)$ & $(1.678)$ & $(1.710)$ \\
Preterm birth & 0.043 & 0.032 & 0.033 & 0.036 \\
Low birth weight & 0.046 & 0.032 & 0.032 & 0.033 \\
Apgar 1min score & 8.741 & 8.798 & 8.850 & 8.891 \\
& $(1.096)$ & $(0.992)$ & $(0.950)$ & $0.903)$ \\
Healthy Apgar score $>=7)$ & 0.958 & 0.968 & 0.971 & 0.975 \\
Female baby & 0.487 & 0.489 & 0.486 & 0.487 \\
Mother married & 0.688 & 0.804 & 0.763 & 0.724 \\
Mother foreign & 0.121 & 0.087 & 0.140 & 0.152 \\
Mother aged 15-19 & 0.056 & 0.013 & 0.009 & 0.009 \\
Mother aged 20-24 & 0.278 & 0.248 & 0.174 & 0.178 \\
Mother aged 25-29 & 0.356 & 0.445 & 0.412 & 0.375 \\
Mother aged 30-34 & 0.221 & 0.230 & 0.312 & 0.323 \\
Mother aged 35-39 & 0.077 & 0.058 & 0.086 & 0.103 \\
Mother aged 40-45 & 0.012 & 0.006 & 0.008 & 0.011 \\
Mother of low SES & 0.519 & 0.529 & 0.464 & 0.436 \\
Worked & 0.759 & 0.611 & 0.607 & 0.563 \\
Days worked & 95.881 & 69.826 & 68.847 & 63.528 \\
\hline Observations & $1,279,374$ & 87,566 & 77,279 & 63,481 \\
\hline \hline
\end{tabular}

Notes: The full sample covers the universe of births occurring from 1984 to 2007 to matched and eligible mothers. Columns (2)-(4) restrict the full sample to second born children with an older sibling that is born 24 months pre- and post a policy reform. The policy reforms considered happen in July 1990 for Column (2), July 1996 for Column (3) and July 2000 for Column (4). 
Table 2: OLS results on preterm and low birth weight

\begin{tabular}{|c|c|c|c|c|}
\hline \multirow{2}{*}{ Dependent Variable } & (1) & $(2)$ & (3) & (4) \\
\hline & \multicolumn{2}{|c|}{ Preterm } & \multicolumn{2}{|c|}{ Low birth weight } \\
\hline \multicolumn{5}{|l|}{ Panel A: Work status } \\
\hline Worked & $\begin{array}{c}-0.0020^{* *} \\
(0.0008)\end{array}$ & $\begin{array}{c}-0.0021^{* * *} \\
(0.0008)\end{array}$ & $\begin{array}{c}-0.0027^{* * *} \\
(0.0008)\end{array}$ & $\begin{array}{c}-0.0023^{* * *} \\
(0.0008)\end{array}$ \\
\hline Sick & $\begin{array}{c}0.0322^{* * *} \\
(0.0018) \\
\end{array}$ & $\begin{array}{c}0.0313^{* * *} \\
(0.0018) \\
\end{array}$ & $\begin{array}{c}0.0314^{* * *} \\
(0.0018) \\
\end{array}$ & $\begin{array}{c}0.0305^{* * *} \\
(0.0018) \\
\end{array}$ \\
\hline \multicolumn{5}{|l|}{ Panel B: Days worked } \\
\hline Days worked & $\begin{array}{c}-0.0001^{* * *} \\
(0.0000)\end{array}$ & $\begin{array}{c}-0.0001^{* * *} \\
(0.0000)\end{array}$ & $\begin{array}{c}-0.0001^{* * *} \\
(0.0000)\end{array}$ & $\begin{array}{c}-0.0001^{* * *} \\
(0.0000)\end{array}$ \\
\hline Sick & $\begin{array}{c}0.0312^{* * *} \\
(0.0018)\end{array}$ & $\begin{array}{c}0.0305^{* * *} \\
(0.0018)\end{array}$ & $\begin{array}{c}0.0305^{* * *} \\
(0.0018)\end{array}$ & $\begin{array}{c}0.0298^{* * *} \\
(0.0018)\end{array}$ \\
\hline Mother Controls & No & Yes & No & Yes \\
\hline Mean Dep. Var. & 0.0335 & 0.0335 & 0.0327 & 0.0327 \\
\hline Observations & 226,824 & 226,824 & 226,824 & 226,824 \\
\hline
\end{tabular}

Notes: This Table is estimated on the pooled sample of the three RDD regression windows. Robust standard errors are reported in parentheses. Additional controls included in all columns are year and month of birth FE, and a gender dummy. Mother's characteristic controls are dummies for 5 year age brackets, marital status, a dummy for low SES (combined from educational and wage data) and a foreign origin dummy. 
Table 3: OLS results on birth weight and gestational length

\begin{tabular}{|c|c|c|c|c|}
\hline \multirow[b]{2}{*}{ Dependent Variable } & (1) & $(2)$ & $(3)$ & $(4)$ \\
\hline & \multicolumn{2}{|c|}{ Birth weight } & \multicolumn{2}{|c|}{ Gestational length } \\
\hline \multicolumn{5}{|l|}{ Panel A: Work status } \\
\hline Worked & $\begin{array}{c}11.3360^{* * *} \\
(2.1728)\end{array}$ & $\begin{array}{c}6.3355^{* * *} \\
(2.2083)\end{array}$ & $\begin{array}{c}0.0136^{*} \\
(0.0073)\end{array}$ & $\begin{array}{c}0.0285^{* * *} \\
(0.0074)\end{array}$ \\
\hline Sick & $\begin{array}{c}-81.5409^{* * *} \\
(4.4193)\end{array}$ & $\begin{array}{c}-80.1422^{* * *} \\
(4.4512)\end{array}$ & $\begin{array}{c}-0.3414^{* * *} \\
(0.0163)\end{array}$ & $\begin{array}{c}-0.3484^{* * *} \\
(0.0165)\end{array}$ \\
\hline \multicolumn{5}{|l|}{ Panel B: Days worked } \\
\hline Days worked & $\begin{array}{c}0.1721^{* * *} \\
(0.0152)\end{array}$ & $\begin{array}{c}0.1530^{* * *} \\
(0.0154)\end{array}$ & $\begin{array}{c}0.0007^{* * *} \\
(0.0000)\end{array}$ & $\begin{array}{c}0.0008^{* * *} \\
(0.0000)\end{array}$ \\
\hline Sick & $\begin{array}{c}-78.7184^{* * *} \\
(4.4173)\end{array}$ & $\begin{array}{c}-78.1331^{* * *} \\
(4.4437)\end{array}$ & $\begin{array}{c}-0.3294^{* * *} \\
(0.0163)\end{array}$ & $\begin{array}{c}-0.3373^{* * *} \\
(0.0164)\end{array}$ \\
\hline Mother Controls & No & Yes & No & Yes \\
\hline Mean Dep. Var. & $3,401.5743$ & $3,401.5743$ & 39.7474 & 39.7474 \\
\hline Observations & 226,824 & 226,824 & 226,824 & 226,824 \\
\hline
\end{tabular}

Notes: This Table is estimated on the pooled sample of the three RDD regression windows. Robust standard errors are reported in parentheses. Additional controls included in all columns are year and month of birth FE, and a gender dummy. Mother's characteristic controls are dummies for 5 year age brackets, marital status, a dummy for low SES (combined from educational and wage data) and a foreign origin dummy. 
Table 4: OLS results on 1 min Apgar scores

\begin{tabular}{lcccc}
\hline \hline Dependent Variable & $(1)$ & $(2)$ & $(3)$ & $(4)$ \\
Panel A: Work status & Apgar 1 min score & Healthy & Apgar score \\
\hline \hline Worked & 0.0023 & 0.0046 & 0.0005 & 0.0006 \\
Sick & $(0.0042)$ & $(0.0042)$ & $(0.0007)$ & $(0.0007)$ \\
& $\begin{array}{c}-0.0849^{* * *} \\
(0.0084)\end{array}$ & $\begin{array}{c}-0.0786^{* * *} \\
-0.0085)\end{array}$ & $(0.0015)$ & $\begin{array}{c}0.0103^{* * *} \\
(0.0015)\end{array}$ \\
\hline \hline Panel B: Days worked & & & & \\
\hline Days worked & $0.0001^{* * *}$ & $0.0001^{* * *}$ & $0.0000^{* * *}$ & $0.0000^{* * *}$ \\
Sick & $(0.0000)$ & $(0.0000)$ & $(0.0000)$ & $(0.0000)$ \\
& $-0.0833^{* * *}$ & $-0.0771^{* * *}$ & $-0.0111^{* * *}$ & $-0.0101^{* * *}$ \\
Mother Controls & $(0.0084)$ & $(0.0084)$ & $(0.0015)$ & $(0.0015)$ \\
\hline Mean Dep. Var. & No & Yes & No & Yes \\
\hline Observations & 8.8413 & 8.8413 & 0.9711 & 0.9711 \\
\hline \hline
\end{tabular}

Notes: This Table is estimated on the pooled sample of the three RDD regression windows. Robust standard errors are reported in parentheses. Additional controls included in all columns are year and month of birth FE, and a gender dummy. Mother's characteristic controls are dummies for 5 year age brackets, marital status, a dummy for low SES (combined from educational and wage data) and a foreign origin dummy. 
Table 5: RDD effects on maternal employment during pregnancy

\begin{tabular}{|c|c|c|c|c|c|c|}
\hline & \multicolumn{2}{|c|}{1990} & \multicolumn{2}{|c|}{1996} & \multicolumn{2}{|c|}{2000} \\
\hline & $(1)$ & $(2)$ & $(3)$ & $(4)$ & $(5)$ & $(6)$ \\
\hline \multicolumn{7}{|c|}{ Panel A: Dependent variable employment status } \\
\hline $1\{$ Post policy reform $\}$ & $\begin{array}{c}-0.191^{* * *} \\
(0.006)\end{array}$ & $\begin{array}{c}-0.191^{* * *} \\
(0.006)\end{array}$ & $\begin{array}{c}0.069^{* * *} \\
(0.007)\end{array}$ & $\begin{array}{c}0.072^{* * *} \\
(0.007)\end{array}$ & $\begin{array}{c}-0.064^{* * *} \\
(0.008)\end{array}$ & $\begin{array}{c}-0.064^{* * *} \\
(0.008)\end{array}$ \\
\hline Comparison Mean & 0.714 & 0.714 & 0.587 & 0.587 & 0.600 & 0.600 \\
\hline \multicolumn{7}{|c|}{ Panel B: Dependent variable days worked } \\
\hline $1\{$ Post policy reform $\}$ & $\begin{array}{c}-23.105^{* * *} \\
(0.924)\end{array}$ & $\begin{array}{c}-23.011^{* * *} \\
(0.891)\end{array}$ & $\begin{array}{c}9.147^{* * *} \\
(0.980)\end{array}$ & $\begin{array}{c}9.493^{* * *} \\
(0.954)\end{array}$ & $\begin{array}{c}-6.712^{* * *} \\
(1.083)\end{array}$ & $\begin{array}{c}-6.636^{* * *} \\
(1.059)\end{array}$ \\
\hline Comparison Mean & 82.720 & 82.720 & 65.607 & 65.607 & 67.369 & 67.369 \\
\hline Additional Mother Controls & No & Yes & No & Yes & No & Yes \\
\hline Observations & 87,566 & 87,566 & 77,279 & 77,279 & 63,481 & 63,481 \\
\hline
\end{tabular}

Notes: This Table is estimated on the matched and eligible sample of second born with an older sibling born within a bandwidth of 24 months around the policy reforms. Robust standard errors are reported in parentheses. Additional mother's characteristic controls include dummies for 5 year age brackets, marital status, a dummy for low SES (combined from educational and wage data) and a foreign origin dummy. The $1\{$ post policy reform $\}$ coefficient estimate reports the impact of a first birth just after the policy reform versus just before. Panel A estimates the effects on employment status and Panel B on the number of days worked during pregnancy with the second child. 
Table 6: RDD effects on newborn health of second born

\begin{tabular}{|c|c|c|c|c|c|c|}
\hline & \multicolumn{2}{|c|}{1990} & \multicolumn{2}{|c|}{1996} & \multicolumn{2}{|c|}{2000} \\
\hline & $(1)$ & $(2)$ & $(3)$ & $(4)$ & $(5)$ & $(6)$ \\
\hline \multicolumn{7}{|c|}{ Panel A: Dependent variable low birth weight } \\
\hline $1\{$ Post policy reform $\}$ & $\begin{array}{c}0.002 \\
(0.002)\end{array}$ & $\begin{array}{c}0.002 \\
(0.002)\end{array}$ & $\begin{array}{l}-0.004 \\
(0.003)\end{array}$ & $\begin{array}{l}-0.004 \\
(0.003)\end{array}$ & $\begin{array}{c}0.001 \\
(0.003)\end{array}$ & $\begin{array}{c}0.001 \\
(0.003)\end{array}$ \\
\hline Comparison Mean & 0.031 & 0.031 & 0.034 & 0.034 & 0.031 & 0.031 \\
\hline \multicolumn{7}{|c|}{ Panel B: Dependent variable preterm } \\
\hline $1\{$ Post policy reform $\}$ & $\begin{array}{c}0.001 \\
(0.003)\end{array}$ & $\begin{array}{c}0.001 \\
(0.002)\end{array}$ & $\begin{array}{l}-0.002 \\
(0.003)\end{array}$ & $\begin{array}{l}-0.002 \\
(0.003)\end{array}$ & $\begin{array}{l}-0.001 \\
(0.003)\end{array}$ & $\begin{array}{l}-0.001 \\
(0.003)\end{array}$ \\
\hline Comparison Mean & 0.034 & 0.032 & 0.033 & 0.033 & 0.035 & 0.035 \\
\hline $\begin{array}{l}\text { Additional Mother Controls } \\
\text { Observations }\end{array}$ & $\begin{array}{c}\text { No } \\
87,566\end{array}$ & $\begin{array}{c}\text { Yes } \\
87,566\end{array}$ & $\begin{array}{c}\text { No } \\
77,279\end{array}$ & $\begin{array}{c}\text { Yes } \\
77,279\end{array}$ & $\begin{array}{c}\text { No } \\
63,481\end{array}$ & $\begin{array}{c}\text { Yes } \\
63,481\end{array}$ \\
\hline
\end{tabular}

Notes: This Table is estimated on the matched and eligible sample of second born with an older sibling born within a bandwidth of 24 months around the policy reforms. Robust standard errors are reported in parentheses. All columns include a gender dummy, year of birth and month of birth fixed effects. Additional mother's characteristic controls include dummies for 5 year age brackets, marital status, a dummy for low SES (combined from educational and wage data) and a foreign origin dummy. The 1 \{post policy reform\} coefficient estimate reports the impact of a first birth just after the policy reform versus just before. Panel A estimates the effects on low birth weight and Panel B on being born preterm. 
Table 7: Robustness - 1990 reform

\begin{tabular}{|c|c|c|c|c|c|c|c|c|}
\hline \multirow[b]{2}{*}{ Dependent variable } & (1) & \multirow[t]{2}{*}{$(2)$} & \multirow{2}{*}{\multicolumn{2}{|c|}{$\begin{array}{l}(3) \\
\text { Days worked }\end{array}$}} & & $(6)$ & $(7)$ & $(8)$ \\
\hline & Wo & & & & \multicolumn{2}{|c|}{ Low birth weight } & \multicolumn{2}{|c|}{ Preterm } \\
\hline \multicolumn{9}{|c|}{ Panel A: excluding 1 week around cutoff } \\
\hline $1\{$ Post policy reform $\}$ & $\begin{array}{c}-0.191^{* * *} \\
(0.007)\end{array}$ & $\begin{array}{c}-0.190^{* * *} \\
(0.006)\end{array}$ & $\begin{array}{c}-22.961^{* * *} \\
(0.942)\end{array}$ & $\begin{array}{c}-22.848^{* * *} \\
(0.908)\end{array}$ & $\begin{array}{c}0.002 \\
(0.003)\end{array}$ & $\begin{array}{c}0.002 \\
(0.003)\end{array}$ & $\begin{array}{l}-0.000 \\
(0.003)\end{array}$ & $\begin{array}{l}-0.000 \\
(0.003)\end{array}$ \\
\hline Observations & 86,702 & 86,702 & 86,702 & 86,702 & 86,702 & 86,702 & 86,702 & 86,702 \\
\hline \multicolumn{9}{|c|}{ Panel B: adding third born } \\
\hline $1\{$ Post policy reform $\}$ & $\begin{array}{c}-0.167^{* * *} \\
(0.006)\end{array}$ & $\begin{array}{c}-0.166^{* * *} \\
(0.006)\end{array}$ & $\begin{array}{c}-20.050^{* * *} \\
(0.811)\end{array}$ & $\begin{array}{c}-19.958^{* * *} \\
(0.785)\end{array}$ & $\begin{array}{l}-0.002 \\
(0.002)\end{array}$ & $\begin{array}{l}-0.002 \\
(0.002)\end{array}$ & $\begin{array}{l}-0.001 \\
(0.002)\end{array}$ & $\begin{array}{l}-0.001 \\
(0.002)\end{array}$ \\
\hline Observations & 113,294 & 113,294 & 113,294 & 113,294 & 113,294 & 113,294 & 113,294 & 113,294 \\
\hline
\end{tabular}

Panel C: Bounds on Treatment Effects

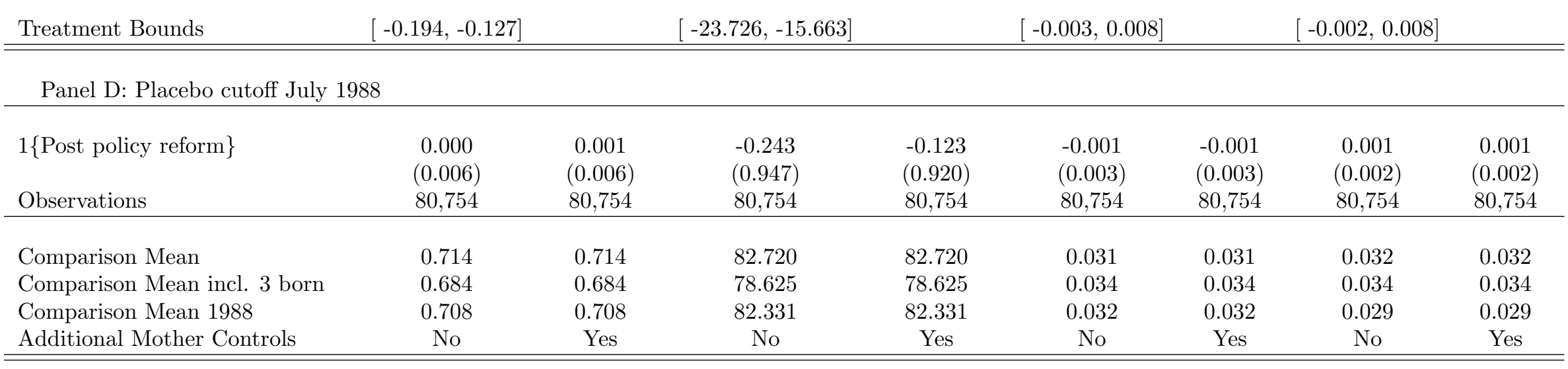

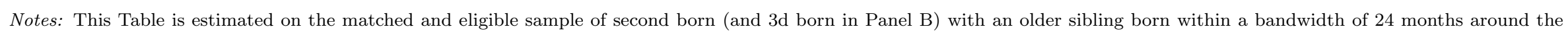

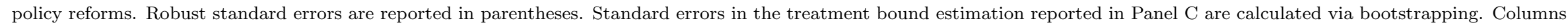

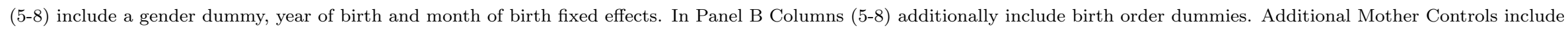

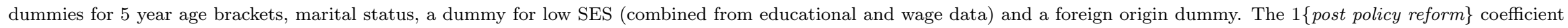

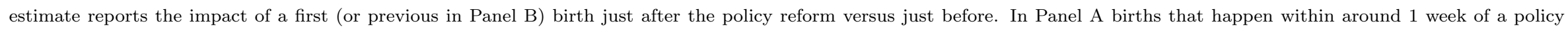

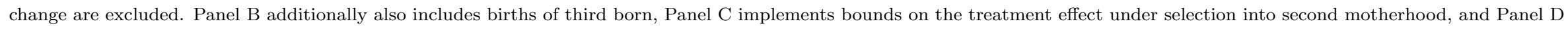
shows Placebo estimates for an imaginary reform in July 1988. 


\section{Appendix}

Figure A1: Percent of second children born within parental leave and grace period

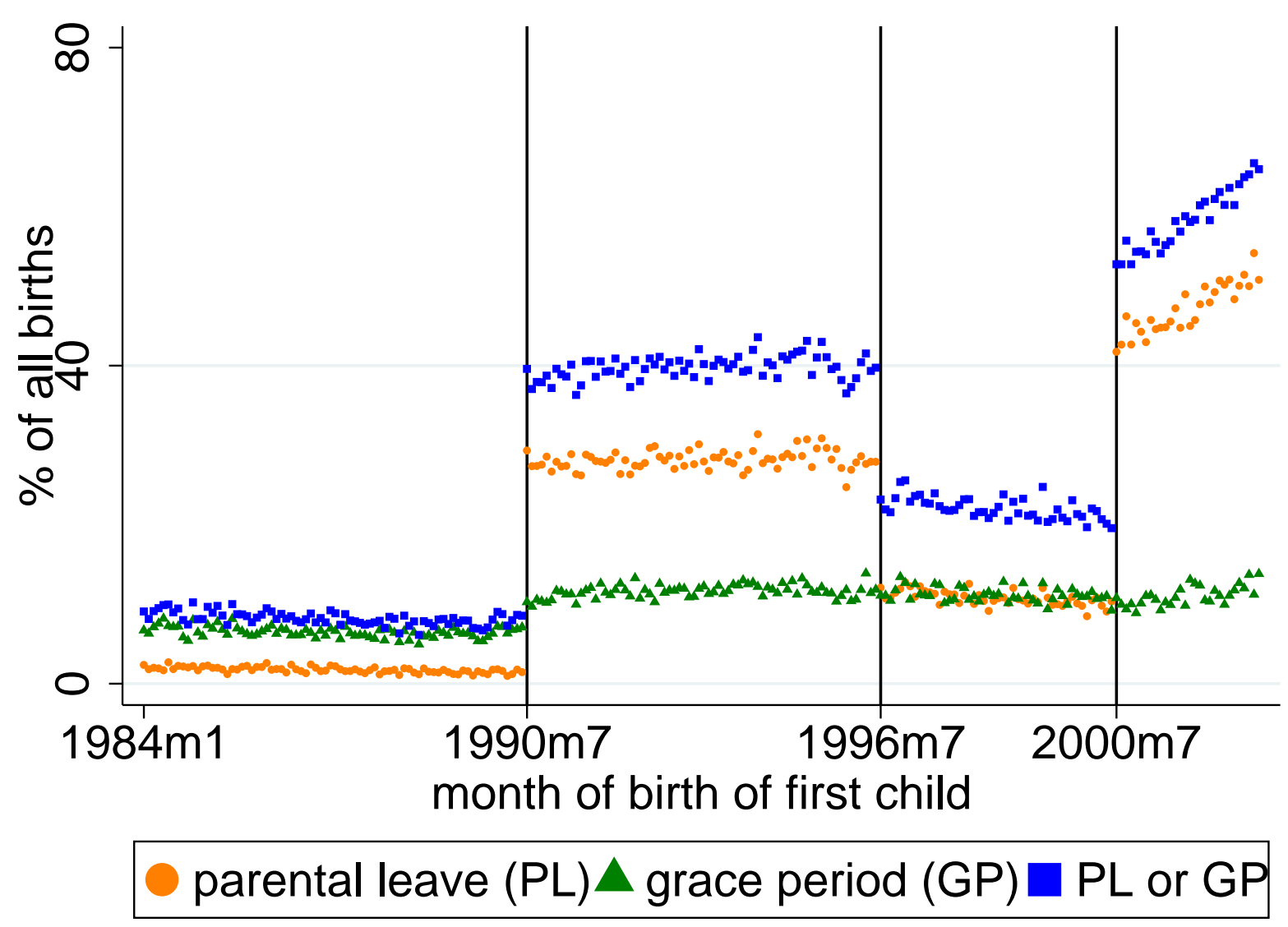

Notes: This Figure shows the fraction of first born in families with at least two children that have a younger sibling that is born within the parental leave and grace period. Orange dots refer to the percentage of second children born within the parental leave period of the first child. Green triangles refer to the percentage of second children born within the grace period after the parental leave period of the first child. Blue squares refer to the sum of both. The solid vertical lines refer to the three policy changes, increasing the latest consecutive birth date to 27.5 months in July 1990, decreasing it to 21.5 months in July 1996 and raising it again to 33.5 months in July 2000. The data consists of the full matched and eligible sample of mothers with at least two children. 
Figure A2: RDD plots - covariates

(a)

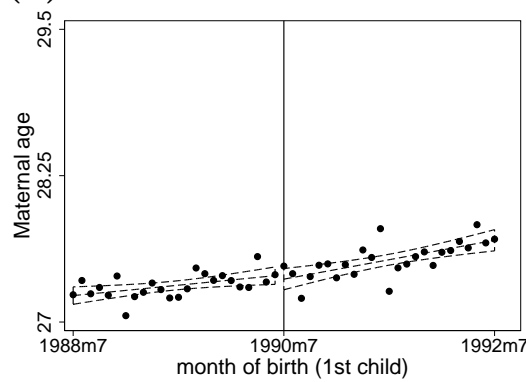

(d)

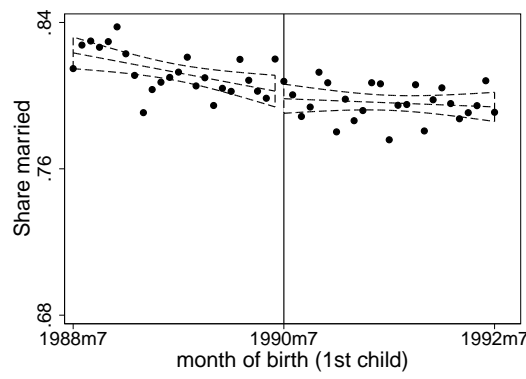

(g)

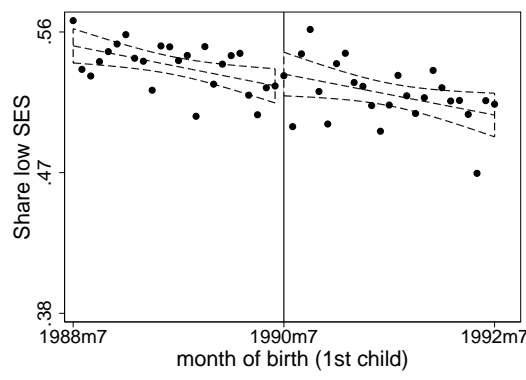

(j)

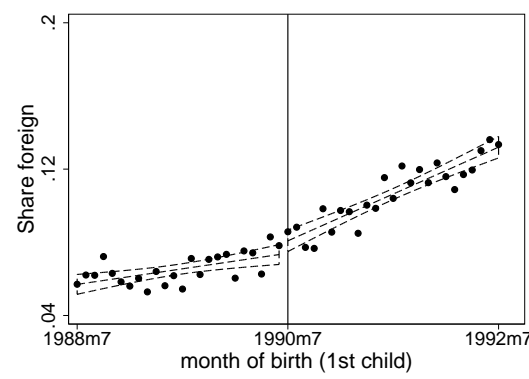

Panel A: Maternal age

(b)

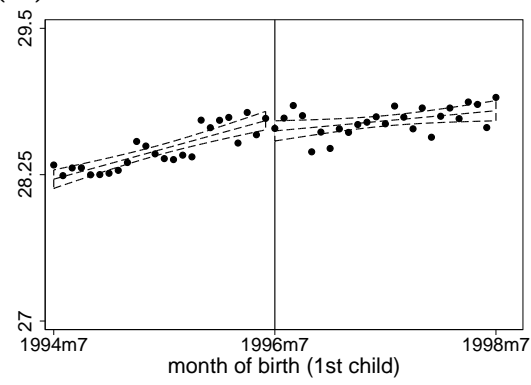

Panel B: Share married

(e)

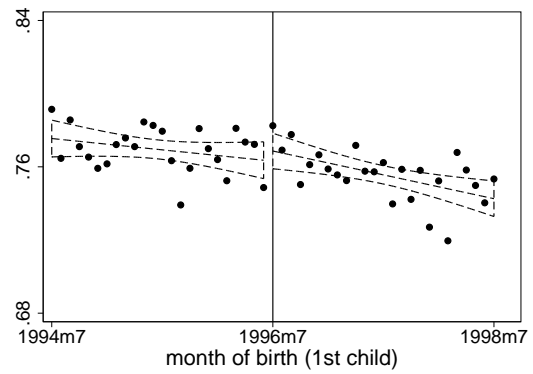

(f)

Panel C: Share low SES

(h)

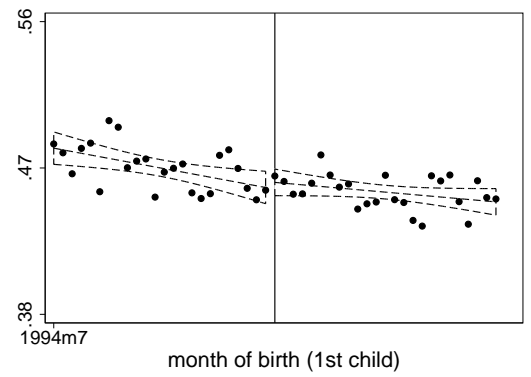

Panel D: Share foreign origin

(k)

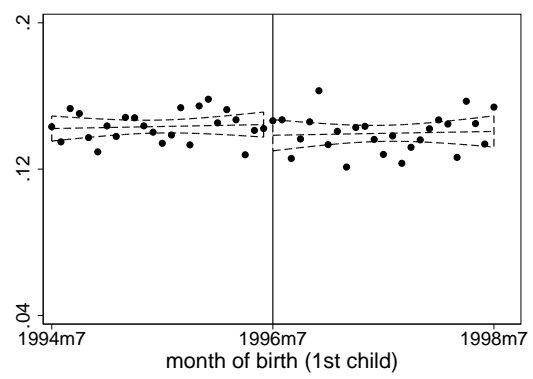

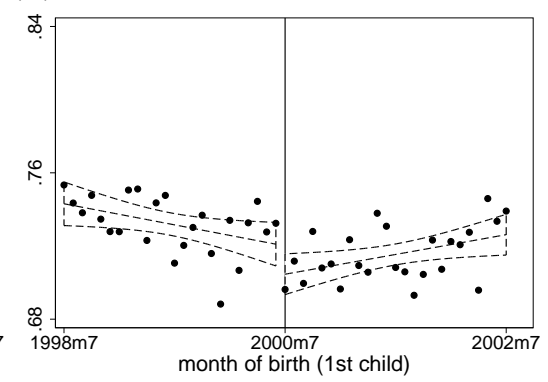

(i)

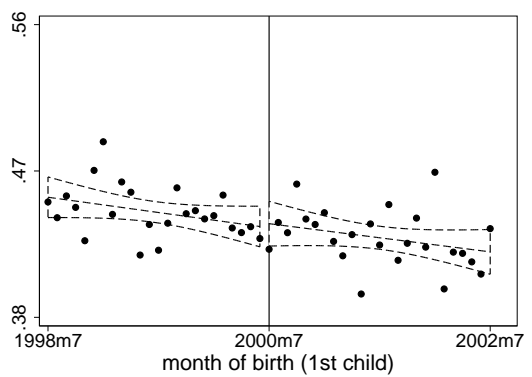

(c)

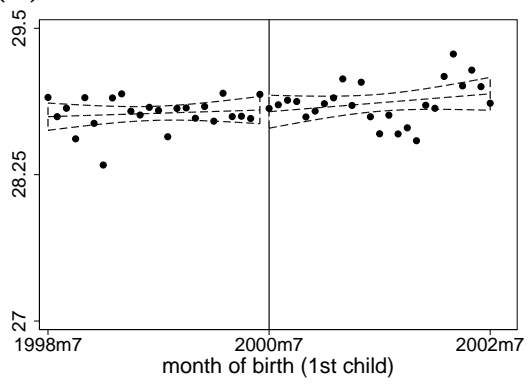

(l)

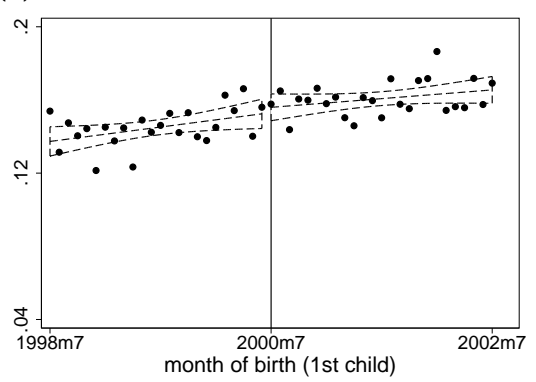

Notes: This Figure reports the composition of mothers giving birth to their second child by month of birth of the first child. All subfigures are based on the full sample of matched and eligible mothers that gave birth to their first child not more than 24 months apart from a policy reform. 
Figure A3: Robustness to different choices of bandwidths - work status and days employed

Panel A: 1990
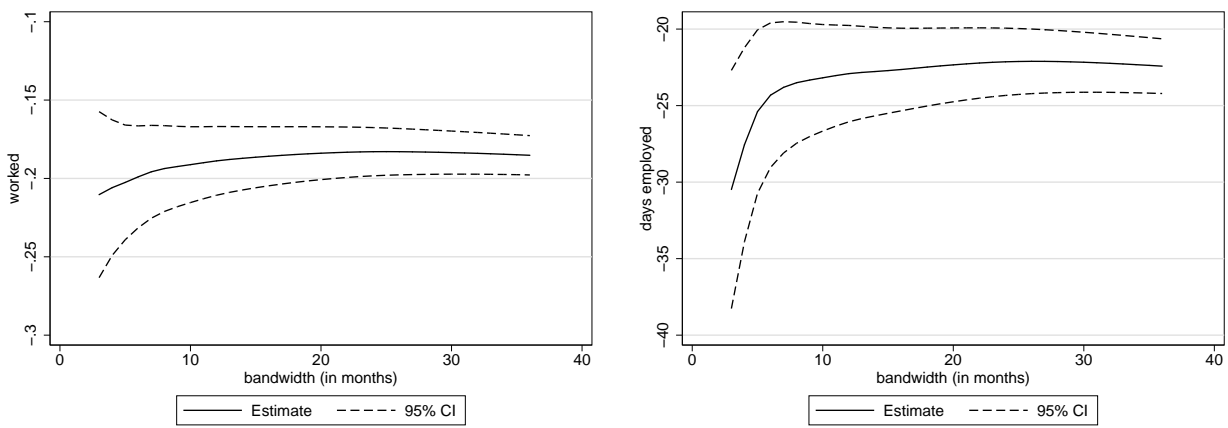

Panel B: 1996
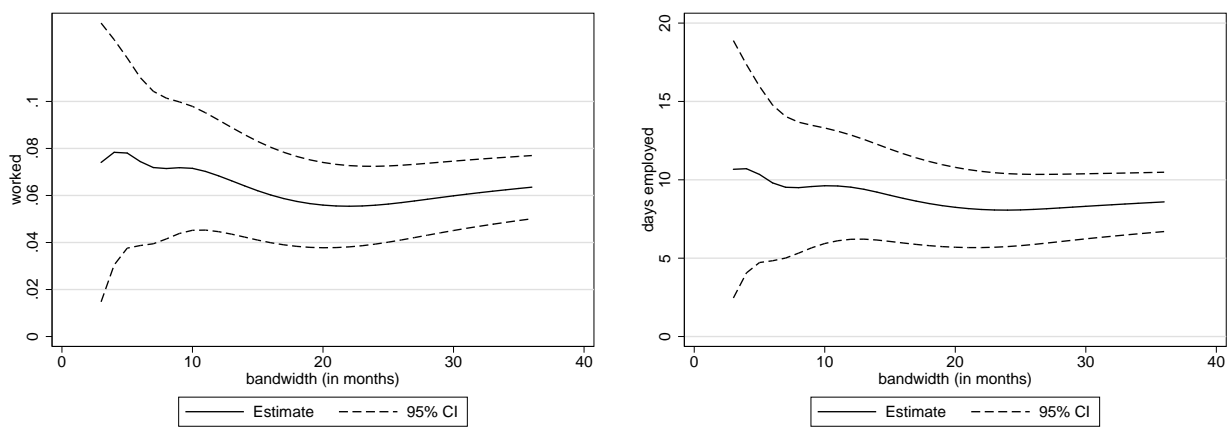

Panel C: 2000
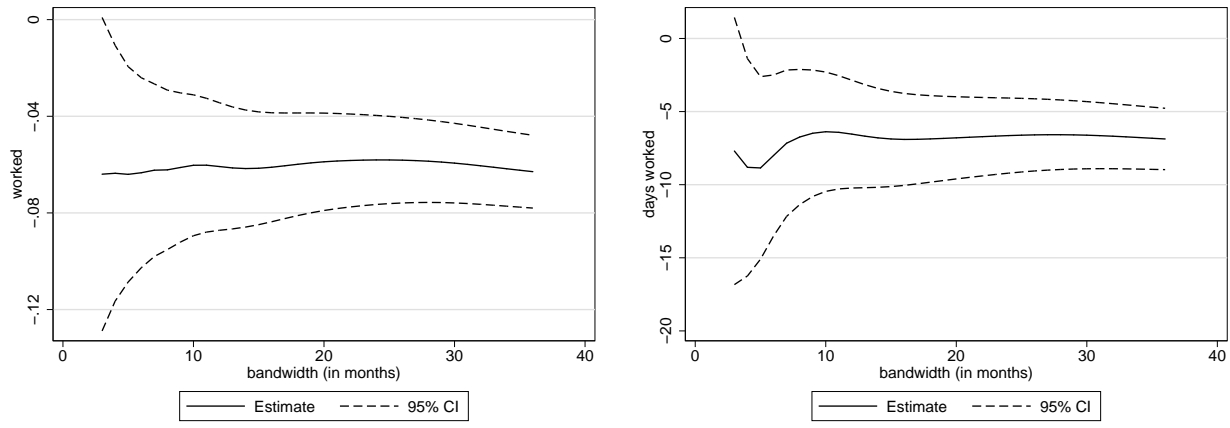

Notes: This Figure reports the robustness of the RDD estimate on the work status and the days employed from Equation (2) to different choices of bandwidths. The solid line refers to the point estimate of separate equations, and the dashed lines indicate the corresponding 95 percent confidence interval. Panel $\mathrm{A}$ and $\mathrm{C}$ refer to the increase in parental leave duration in July 1990 and July 2000, respectively. Panel B shows the policy reform in July 1996, where parental leave duration declined. All Panels were estimated using the full sample of matched and eligible mothers. 
Figure A4: RDD estimates for different thresholds - 1990 reform

Panel A: Birth weight

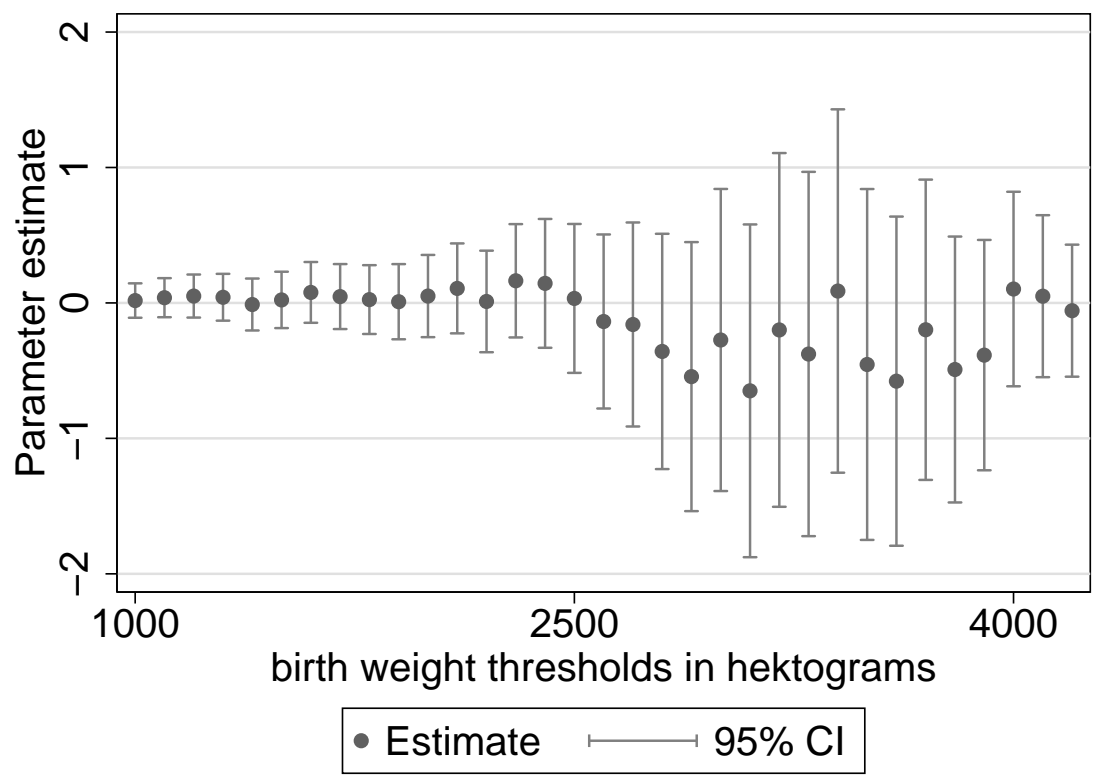

Panel B: Gestational age

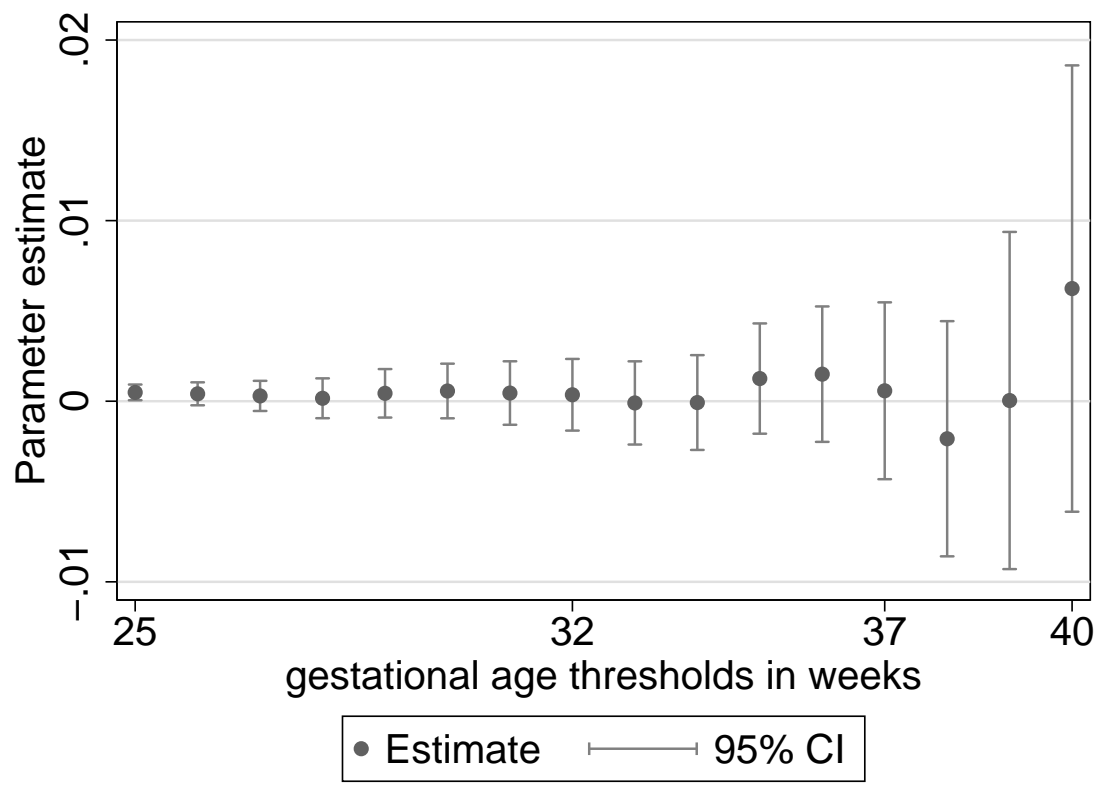

Notes: This Figure reports parameter estimates for the coefficient $\delta_{1}$ in Equation (3). In Panel A (B) for every 100 grams (week) a separate regression is estimated, corresponding to another birth weight (gestational age) threshold than the one used in the paper of 2,500 grams (37 weeks). 95 percent confidence intervals are shown by vertical lines. All estimates are based on regressions including the full set of controls. The sample consists of all matched and eligible mothers that gave birth to their first child not more than 24 months apart from the policy reform in July 1990. 
Table A1: Covariate balance test

\begin{tabular}{lccc}
\hline \hline & $\begin{array}{c}1990 \\
(1)\end{array}$ & $\begin{array}{c}1996 \\
(2)\end{array}$ & $\begin{array}{c}2000 \\
(3)\end{array}$ \\
\hline \hline Panel A: Dependent variable maternal age & & & \\
\hline \multirow{2}{*}{ Post policy reform\} } & -0.032 & -0.096 & -0.004 \\
& $(0.059)$ & $(0.062)$ & $(0.072)$ \\
Comparison Mean & 27.412 & 28.735 & 28.822 \\
\hline \hline \multirow{2}{*}{ Panel B: Dependent variable married } & & & \\
\hline \multirow{2}{*}{ Post policy reform $\}$} & & & \\
& -0.003 & 0.006 & $-0.014^{* *}$ \\
Comparison Mean & $(0.005)$ & $(0.006)$ & $(0.007)$ \\
\hline \hline
\end{tabular}

Panel C: Dependent variable share low SES

\begin{tabular}{lccc}
$1\{$ Post policy reform $\}$ & 0.008 & 0.005 & 0.001 \\
& $(0.007)$ & $(0.007)$ & $(0.008)$ \\
Comparison Mean & 0.522 & 0.456 & 0.432 \\
\hline \hline
\end{tabular}

Panel D: Dependent variable share foreign origin

\begin{tabular}{lccc}
\hline 1 Post policy reform\} & $0.007^{*}$ & -0.006 & 0.003 \\
Comparison Mean & $(0.004)$ & $(0.005)$ & $(0.006)$ \\
Observations & 0.073 & 0.144 & 0.152 \\
\hline
\end{tabular}

Notes: This Table is estimated on the matched and eligible sample of second born with an older sibling born within a bandwidth of 24 months around the policy reforms. Robust standard errors are reported in parentheses. The 1 \{post policy reform\} coefficient estimate reports the impact of a first birth just after the policy reform versus just before. 
Table A2: OLS results on preterm and low birth weight - Full set of mother characteristic controls

\begin{tabular}{|c|c|c|c|c|}
\hline & (1) & (2) & (3) & (4) \\
\hline Dependent Variable & \multicolumn{2}{|c|}{ Preterm } & \multicolumn{2}{|c|}{ Low birth weight } \\
\hline \multicolumn{5}{|l|}{ Panel A: Work status } \\
\hline Worked & $\begin{array}{c}-0.0020^{* *} \\
(0.0008)\end{array}$ & $\begin{array}{c}-0.0021^{* * *} \\
(0.0008)\end{array}$ & $\begin{array}{c}-0.0027^{* * *} \\
(0.0008)\end{array}$ & $\begin{array}{c}-0.0023^{* * *} \\
(0.0008)\end{array}$ \\
\hline Sick & $\begin{array}{c}0.0322^{* * *} \\
(0.0018)\end{array}$ & $\begin{array}{c}0.0313^{* * *} \\
(0.0018)\end{array}$ & $\begin{array}{c}0.0314^{* * *} \\
(0.0018)\end{array}$ & $\begin{array}{c}0.0305^{* * *} \\
(0.0018)\end{array}$ \\
\hline Married & & $\begin{array}{c}-0.0056^{* * *} \\
(0.0010)\end{array}$ & & $\begin{array}{c}-0.0094^{* * *} \\
(0.0010)\end{array}$ \\
\hline Foreign & & $\begin{array}{c}0.0047^{* * *} \\
(0.0013)\end{array}$ & & $\begin{array}{c}-0.0003^{* * *} \\
(0.0012)\end{array}$ \\
\hline Aged 20-24 & & $\begin{array}{c}-0.0185^{* * *} \\
(0.0047)\end{array}$ & & $\begin{array}{c}-0.0184^{* * *} \\
(0.0048)\end{array}$ \\
\hline Aged 25-29 & & $\begin{array}{c}-0.0202^{* * *} \\
(0.0047)\end{array}$ & & $\begin{array}{c}-0.0214^{* * *} \\
(0.0048)\end{array}$ \\
\hline Aged 30-34 & & $\begin{array}{c}-0.0149^{* * *} \\
(0.0048)\end{array}$ & & $\begin{array}{c}-0.0173^{* * *} \\
(0.0048)\end{array}$ \\
\hline Aged 35-39 & & $\begin{array}{l}-0.0027 \\
(0.0050)\end{array}$ & & $\begin{array}{c}-0.0027 \\
(0.0051)\end{array}$ \\
\hline Aged 40-45 & & $\begin{array}{l}0.0139^{*} \\
(0.0074)\end{array}$ & & $\begin{array}{c}0.0110 \\
(0.0074)\end{array}$ \\
\hline Low SES & & $\begin{array}{c}0.0034^{* * *} \\
(0.0008)\end{array}$ & & $\begin{array}{c}0.0044^{* * *} \\
(0.0008)\end{array}$ \\
\hline
\end{tabular}

Panel B: Days worked

\begin{tabular}{|c|c|c|c|c|}
\hline Days worked & $\begin{array}{c}-0.0001^{* * *} \\
(0.0000)\end{array}$ & $\begin{array}{c}-0.0001^{* * *} \\
(0.0000)\end{array}$ & $\begin{array}{c}-0.0001^{* * *} \\
(0.0000)\end{array}$ & $\begin{array}{c}-0.0001^{* * *} \\
(0.0000)\end{array}$ \\
\hline Sick & $\begin{array}{c}0.0312^{* * *} \\
(0.0018)\end{array}$ & $\begin{array}{c}0.0305^{* * *} \\
(0.0018)\end{array}$ & $\begin{array}{c}0.0305^{* * *} \\
(0.0018)\end{array}$ & $\begin{array}{c}0.0298^{* * *} \\
(0.0018)\end{array}$ \\
\hline Married & & $\begin{array}{c}-0.0054^{* * *} \\
(0.0010)\end{array}$ & & $\begin{array}{c}-0.0092^{* * *} \\
(0.0010)\end{array}$ \\
\hline Foreign & & $\begin{array}{c}0.0045^{* * *} \\
(0.0013)\end{array}$ & & $\begin{array}{c}-0.0005^{* * *} \\
(0.0012)\end{array}$ \\
\hline Aged 20-24 & & $\begin{array}{c}-0.0176^{* * *} \\
((11.0632))\end{array}$ & & $\begin{array}{c}-0.0177^{* * *} \\
(0.0048)\end{array}$ \\
\hline Aged 25-29 & & $\begin{array}{c}-0.0185^{* * *} \\
(0.0047)\end{array}$ & & $\begin{array}{c}-0.0201^{* * *} \\
(0.0048)\end{array}$ \\
\hline Aged 30-34 & & $-0.0126^{* * *}$ & & $-0.0155^{* * *}$ \\
\hline
\end{tabular}


(0.0048)

(0.0048)

Aged 35-39

$-0.0001$

$-0.0008$

(0.0050)

(0.0051)

Aged 40-45

$0.0165^{* *}$

$0.0130^{* * *}$

(0.0074)

(0.0074)

Low SES

$0.0032^{* * *}$

$0.0043^{* * *}$

(0.0008)

(0.0008)

\begin{tabular}{lcccc}
\hline Mother Controls & No & Yes & No & Yes \\
\hline Mean Dep. Var. & 0.0335 & 0.0335 & 0.0327 & 0.0327 \\
\hline Observations & 226,824 & 226,824 & 226,824 & 226,824 \\
\hline
\end{tabular}

Notes: This Table is estimated on the pooled sample of the three RDD regression windows. Robust standard errors are reported in parentheses. Additional controls included in all columns are year and month of birth FE, and a gender dummy. Mother's characteristic controls are dummies for 5 year age brackets, marital status, a dummy for low SES (combined from educational and wage data) and a foreign origin dummy. 
Table A3: Robustness to different functional forms - 1990 reform

\begin{tabular}{|c|c|c|c|c|c|c|c|c|}
\hline & $(1)$ & $(2)$ & $(3)$ & $(4)$ & $(5)$ & $(6)$ & $(7)$ & $(8)$ \\
\hline \multicolumn{9}{|c|}{ Panel A: Dependent variable work status } \\
\hline $1\{$ Post policy reform $\}$ & $\begin{array}{c}-0.191^{* * *} \\
(0.006)\end{array}$ & $\begin{array}{c}-0.190^{* * *} \\
(0.006)\end{array}$ & $\begin{array}{c}-0.191^{* * *} \\
(0.006)\end{array}$ & $\begin{array}{c}-0.191^{* * *} \\
(0.006)\end{array}$ & $\begin{array}{c}-0.191^{* * *} \\
(0.006)\end{array}$ & $\begin{array}{c}-0.190^{* * *} \\
(0.006)\end{array}$ & $\begin{array}{c}-0.185^{* * *} \\
(0.010)\end{array}$ & $\begin{array}{c}-0.183^{* * *} \\
(0.009)\end{array}$ \\
\hline Comparison Mean & 0.713 & 0.713 & 0.714 & 0.714 & 0.712 & 0.712 & 0.716 & 0.716 \\
\hline \multicolumn{9}{|c|}{ Panel B: Dependent variable days worked } \\
\hline $1\{$ Post policy reform $\}$ & $\begin{array}{c}-22.965^{* * *} \\
(0.919)\end{array}$ & $\begin{array}{c}-22.802^{* * *} \\
(0.885)\end{array}$ & $\begin{array}{c}-23.105^{* * *} \\
(0.924)\end{array}$ & $\begin{array}{c}-23.011^{* * *} \\
(0.891)\end{array}$ & $\begin{array}{c}-23.042^{* * *} \\
(0.922)\end{array}$ & $\begin{array}{c}-22.933^{* * *} \\
(0.888)\end{array}$ & $\begin{array}{c}-22.244^{* * *} \\
(1.401)\end{array}$ & $\begin{array}{c}-22.030^{* * *} \\
(1.349)\end{array}$ \\
\hline Comparison Mean & 82.104 & 82.104 & 82.720 & 82.720 & 82.400 & 82.400 & 82.825 & 82.825 \\
\hline Additional Mother Controls & No & Yes & No & Yes & No & Yes & No & Yes \\
\hline Observations & 87,566 & 87,566 & 87,566 & 87,566 & 87,566 & 87,566 & 87,566 & 87,566 \\
\hline Spline & Linear & Linear & $\begin{array}{c}\text { Linear } \\
\text { Interaction }\end{array}$ & $\begin{array}{c}\text { Linear } \\
\text { Interaction }\end{array}$ & Quadratic & Quadratic & $\begin{array}{l}\text { Quadratic } \\
\text { Interaction }\end{array}$ & $\begin{array}{l}\text { Quadratic } \\
\text { Interaction }\end{array}$ \\
\hline
\end{tabular}

Notes: This Table is estimated on the matched and eligible sample of second born with an older sibling born within a bandwidth of 24 months around the policy reforms. Robust standard errors are reported in parentheses. Additional mother's characteristic controls include dummies for 5 year age brackets, marital status, a dummy for low SES (combined from educational and wage data) and a foreign origin dummy. The $1\{$ post policy reform\} coefficient estimate reports the impact of a first birth on maternal employment just after the policy reform versus just before. The models that are tested are linear, linear interaction, quadratic, and quadratic interaction as described by Jacob et al. (2012). 
Table A4: Age differences in detail

\begin{tabular}{|c|c|c|c|}
\hline & $\begin{array}{c}1990 \text { sample } \\
\text { (1) }\end{array}$ & $\begin{array}{c}1996 \text { sample } \\
\text { (2) }\end{array}$ & $\begin{array}{c}2000 \text { sample } \\
\text { (3) }\end{array}$ \\
\hline 0-18 months & $\begin{array}{c}-0.040^{* * *} \\
(0.005)\end{array}$ & $\begin{array}{c}0.039^{* * *} \\
(0.004)\end{array}$ & $\begin{array}{l}-0.006 \\
(0.005)\end{array}$ \\
\hline 0-36 months & $\begin{array}{c}0.021^{* * *} \\
(0.006)\end{array}$ & $\begin{array}{c}0.002 \\
(0.007)\end{array}$ & $\begin{array}{l}-0.007 \\
(0.008)\end{array}$ \\
\hline 0-120 months & $\begin{array}{c}0.004^{*} \\
(0.002)\end{array}$ & $\begin{array}{c}0.004^{* * *} \\
(0.001)\end{array}$ & \\
\hline 0-16 months & $\begin{array}{c}-0.030^{* * *} \\
(0.004)\end{array}$ & & \\
\hline 17-28 months & $\begin{array}{c}0.057^{* * *} \\
(0.006)\end{array}$ & & \\
\hline 29-120 months & $\begin{array}{c}-0.023^{* * *} \\
(0.007)\end{array}$ & & \\
\hline 0-22 months & & $\begin{array}{c}0.046^{* * *} \\
(0.006)\end{array}$ & \\
\hline 23-28 months & & $\begin{array}{c}-0.050^{* * *} \\
(0.005)\end{array}$ & \\
\hline 29-120 months & & $\begin{array}{c}0.009 \\
(0.007)\end{array}$ & \\
\hline 0-22 months & & & $\begin{array}{c}-0.031^{* * *} \\
(0.007)\end{array}$ \\
\hline 23-34 months & & & $\begin{array}{l}0.018^{* *} \\
(0.007)\end{array}$ \\
\hline 35-120 months & & & $\begin{array}{c}0.013^{*} \\
(0.008)\end{array}$ \\
\hline Observations & 87,413 & 76,943 & 63,134 \\
\hline
\end{tabular}

Notes: This Table is estimated on the matched and eligible sample of second born with an older sibling born within a bandwidth of 24 months around the policy reforms. Robust standard errors are reported in parentheses. This table reports the 1 post policy reform\} parameter estimate on the respective age difference between first and second born child. All columns include mother's characteristic controls for 5 year age brackets, marital status, a dummy for low SES (combined from educational and wage data) and a foreign origin dummy. 